\title{
Metabolism and Modification of Apolipoprotein B-Containing Lipoproteins Involved in Dyslipidemia and Atherosclerosis
}

\author{
Shin-ya Morita \\ Department of Pharmacy, Shiga University of Medical Science Hospital; \\ Otsu, Shiga 520-2192, Japan. \\ Received September 17, 2015
}

\begin{abstract}
Increased levels of apolipoprotein B (apoB)-containing lipoproteins, such as low density lipoproteins (LDL) and chylomicron remnants, are associated with the development of atherosclerosis. Chylomicrons containing apoB-48 are secreted from the intestine during the postprandial state, whereas very low density lipoproteins (VLDL) containing apoB-100 are constitutively formed in the liver. Chylomicron remnants and VLDL remnants are produced by the lipoprotein lipase-mediated lipolysis of triglycerides, which is activated by apolipoprotein $\mathrm{C}$-II bound on the particle surfaces. The hepatic uptake of these remnants is facilitated by apolipoprotein $\mathrm{E}$ (apoE), but is inhibited by apolipoproteins C-I, C-II and C-III. In the plasma, VLDL remnants are further converted into LDL by the hydrolysis of triglycerides. ApoB-100 is responsible for the hepatic uptake of LDL. LDL receptor, LDL receptor-related protein and heparan sulfate proteoglycans are involved in the hepatic clearance of lipoproteins containing apoB-100 and/or apoE. The subendothelial retention and modification of apoB-containing lipoproteins are crucial events in the initiation of atherosclerosis. In the subendothelium, the uptake of modified lipoproteins by macrophages leads to the formation of foam cells storing excess amounts of cholesteryl esters and subsequently to apoptosis. This review describes the current knowledge about the metabolism and modification of apoB-containing lipoproteins involved in dyslipidemia and atherogenesis. In particular, I focus on the effects of apolipoproteins, lipid composition and particle size on lipoprotein metabolism and on the roles of cholesterol, sphingomyelinase and apoB denaturation in macrophage foam cell formation and apoptosis. A detailed understanding of these mechanisms will help to develop new therapeutic strategies.
\end{abstract}

Key words lipoprotein; apolipoprotein; cholesterol; sphingomyelinase; foam cell formation; apoptosis

\section{INTRODUCTION}

Plasma lipoproteins consist of a hydrophobic core containing triglycerides (TG) and cholesteryl esters (CE), a surface monolayer containing phospholipids (PL) and unesterified (free) cholesterol (FC), and surface-bound apolipoproteins (Fig. 1A). The main PL components of lipoproteins are phosphatidylcholine (PC) and sphingomyelin (SM). The lipoprotein core also contains small amounts of lipid-soluble vitamins. Based on the densities determined by the relative contents of lipids and proteins, lipoproteins are classified into chylomicrons $(\mathrm{CM})(<0.94 \mathrm{~g} / \mathrm{mL})$, very low density lipoproteins (VLDL) $(0.94-1.006 \mathrm{~g} / \mathrm{mL})$, intermediate density lipoproteins (IDL) $(1.006-1.019 \mathrm{~g} / \mathrm{mL})$, low density lipoproteins (LDL) (1.019-1.063 g/mL), and high density lipoproteins (HDL) $(1.063-1.210 \mathrm{~g} / \mathrm{mL}){ }^{1)} \mathrm{CM}$ is very large spherical particles (75-450 nm diameter) containing only one molecule of apoB-48. CM is formed in the intestine and transports dietary TG and cholesterol to the liver and peripheral tissues (Fig. 2). On the other hand, VLDL $(60-80 \mathrm{~nm}$ diameter) is synthesized in the liver and contains a single copy of apoB-100. In the plasma, CM remnants and IDL, also called VLDL remnants, are formed by the lipoprotein lipase (LPL)-mediated lipolysis of TG. Although VLDL remnants are partially cleared by the liver, a large part of VLDL remnants are converted into LDL by further hydrolysis of TG. Thus, LDL (18-25 nm diameter) also contains a single copy of apoB-100. ${ }^{2}$ These apoB-containing lipoproteins also bind the exchangeable apolipoproteins, such as apolipoprotein A-I (apoA-I), apolipoprotein C-I
(apoC-I), apolipoprotein C-II (apoC-II), apolipoprotein C-III (apoC-III), and apolipoprotein E (apoE). On the other hand, HDL (7.2-12 nm diameter) is formed from peripheral tissues, and has mainly apoA-I but no apoB. ${ }^{3)}$ The apolipoprotein composition is characteristic of each lipoprotein class.

A high level of plasma LDL is a strong risk factor for atherosclerosis, while a high level of HDL is protective against atherosclerosis. There are a positive correlation between LDL-cholesterol levels and coronary heart disease (CHD) and an inverse relationship between HDL-cholesterol levels and CHD. $^{4,5)}$ Plasma TG level is a significant predictor of CHD, but is weaker as an independent risk factor than LDL-cholesterol level or HDL-cholesterol level. ${ }^{6}$ Statin treatment reduces coronary events and improves survival, which is attributed to the reduction in LDL-cholesterol. ${ }^{4,5)} \mathrm{CM}$ remnants are also known to be atherogenic. ${ }^{7)}$ Patients with postprandial hyperlipidemia have premature clinical signs of atherosclerosis. ${ }^{8,9)}$ In addition, the levels of lipoprotein (a) (Lp(a)) are strongly connected with increased risk of atherosclerotic vascular disease. ${ }^{10)}$ The level of small dense LDL (sdLDL) cholesterol is a significant independent determinant of CHD risk. ${ }^{11)}$

Lipid emulsion particles have been used as models for plasma lipoproteins. However, the lipid emulsions may not necessarily represent the nature of lipoproteins owing notably to the lack of apoB. ApoB plays a crucial role in the maintenance of the lipoprotein structure, but cannot be properly reconstituted on emulsion particles at present. However, lipid emulsions are useful to elucidate the mechanisms of lipoprotein metabolism, because they enable easy control of the lipid and protein con- 
stituents and the size of the particles.

\section{METABOLISM OF APOB-CONTAINING LIPOPROTEINS}

2.1. Lipoprotein Assembly In humans, apoB-48 is used for $\mathrm{CM}$ assembly in intestinal enterocytes during the postprandial state, whereas apoB-100 is used for the constitutive formation of VLDL in hepatocytes (Fig. 2). It has been proposed that intestinal and hepatic lipoprotein assembly begins with the synthesis of primordial lipoproteins. ${ }^{12-14)}$ This step involves the release of apoB with lipids derived from the endoplasmic reticulum (ER) membrane to the ER lumen, and is critically dependent on the lipid transfer activity of microsomal triglyceride transfer protein (MTP). Proper folding and stability of apoB requires the MTP-dependent transfer of both polar and neutral lipids from the ER membrane or some other donor site to nascent apoB during translation. The primordial lipoproteins are relatively small dense particles with a maximum diameter of approximately $25 \mathrm{~nm}$ and consist of apoB associated with PL monolayer with some TG. In addition, progressively larger TG-rich lipid droplets of different sizes are formed in the ER lumen, and their synthesis occurs independent of apoB synthesis. MTP transfers TG to these droplets, and facilitates their formation. The TG-rich lipid droplets are assumed to fuse with primordial lipoproteins in a process called core expansion. This step may be crucial in rendering these droplets secretion-competent and may be the rate-limiting step that determines the transport of TG from ER to the Golgi complex. These partially matured lipoproteins are delivered to the Golgi for final processing prior to secretion. ${ }^{15)}$ The transport of TG-rich particles out of the ER to the Golgi complex is facilitated by the acquisition of apoB. ApoB-48, apoA-I, apolipoprotein A-IV (apoA-IV), apoCs are associated with nascent $\mathrm{CM}$.

In abetalipoproteinemia, deficiency in intestinal lipoprotein assembly and secretion results in malabsorption of dietary fat and fat-soluble vitamins. ${ }^{16)}$ Patients are characterized by severe fat malabsorption and TG accumulation in enterocytes. The synthesis of intestinal CM and liver VLDL is absent in abetalipoproteinemia due to a defect in the MTP activity. ${ }^{17,18)}$ MTP is an ER-localized heterodimeric protein, which is composed of a $97-\mathrm{kDa}$ subunit complexed with the ubiquitous ER-folding enzyme protein disulfide isomerase. ${ }^{19)}$ The $97 \mathrm{kDa}$ MTP subunit is necessary for lipid transfer activity. The protein disulfide isomerase subunit containing an ER retention signal is important to retain the MTP subunit in the lumen of the ER. Expression of apoB without MTP leads to the intracellular degradation of apoB.

In $\mathrm{CM}$ retention disease, the assembly and secretion of apoB-containing lipoproteins is impaired only in the intestine but not in the liver. ${ }^{20,21)} \mathrm{CM}$ retention disease is characterized by diarrhea with steatorrhea, typical lipid-filled enterocytes, and low plasma cholesterol levels. However, apoB-48 synthesis and MTP levels appear normal in the intestine. ${ }^{18,22)} \mathrm{CM}$ retention disease is a specific defect of intestinal lipoprotein secretion. The $S A R 1 B$ gene is responsible for $\mathrm{CM}$ retention disease and encodes the Sarlb protein, which is involved in the CM transport from the ER to the Golgi apparatus. ${ }^{23)}$

Mipomersen, an apoB antisense oligonucleotide, reduces LDL cholesterol, apoB, and Lp(a) in both homozygous and heterozygous familial hypercholesterolemia patients. ${ }^{24,25)}$ The administration of lomitapide, a MTP inhibitor, results in reductions of LDL cholesterol, apoB and TG and has no significant effect on $\mathrm{Lp}(\mathrm{a}){ }^{26)}$

2.2. Lipolysis of Lipoproteins Nascent CM secreted into the lymphatic system enter the circulation via the thoracic duct. ${ }^{7)}$ The heart and lung are the first organs encountering postprandial CM, and these two organs are the sites of the robust expression of LPL (Fig. 2). LPL is associated with the luminal side of capillaries and arteries, and hydrolyzes TG to produce free fatty acids. The hydrolysis results in the delivery of free fatty acids to peripheral tissues. LPL converts CM to remnants and begins the cascade required for the conversion of VLDL to LDL. Some LPL dissociates from endothelial cells during lipolysis and continues to hydrolyze lipoprotein TG in the bloodstream. ${ }^{27)} \mathrm{CM}$ TG clearance is much faster than VLDL TG clearance. ${ }^{27,28)}$ Larger VLDL particles are removed from the bloodstream before their conversion to LDL, whereas more small VLDL particles are converted to LDL. ${ }^{29}$ Smaller, but not larger, VLDL particles are also substrates for hepatic triglyceride lipase (HL). ${ }^{27)}$ Plasma LPL is correlated with plasma free fatty acid levels. ${ }^{30)}$ ApoC-II present in CM and VLDL acts as the activator of LPL. Newly formed CM that is isolated from the lymph before entry into the circulation contains very little apoC-II. ${ }^{31)}$ There is an exchange of apoCs and apoE on HDL for apoA-I and apoA-IV on CM. ${ }^{27)}$

Cholesteryl ester transfer protein (CETP), a plasma protein of 476 amino acid residues, catalyzes non-directional equimolar exchange of nonpolar lipids, $\mathrm{CE}$ and TG, among lipoprotein subfractions. ${ }^{32} \mathrm{CE}$ is actively generated in plasma HDL

Dr. Shin-ya Morita was born in Kyoto, Japan, in 1977. After graduating from the Faculty of Pharmaceutical Sciences at Kyoto University in 2000, he studied in the Graduate School of Pharmaceutical Sciences at Kyoto University under the supervision of Prof. Tetsurou Handa and obtained his Ph.D. degree from the university in 2005. He then joined the research group of Prof. Kazumitsu Ueda in the Graduate School of Agriculture at Kyoto University as a Research Fellow of the Japan Society for the Promotion of Science. In 2006, he moved to the group of Prof. Shuji Kitagawa at Kobe Pharmaceutical University as an Assistant Professor. In 2011, he was appointed an Associate Professor in the Department of Pharmacy (Prof. Tomohiro Terada) at Shiga University of Medical Science Hospital. He was awarded the Membrane Society of Japan Award for Young Investigators in 2012 and the

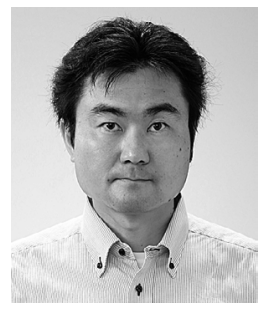

Shin-ya Morita Pharmaceutical Society of Japan Award for Young Scientists in 2015. His major research fields are the biophysics and biochemistry of lipids and clinical pharmacy. He also works on the development of the methods for measuring lipids. 
A
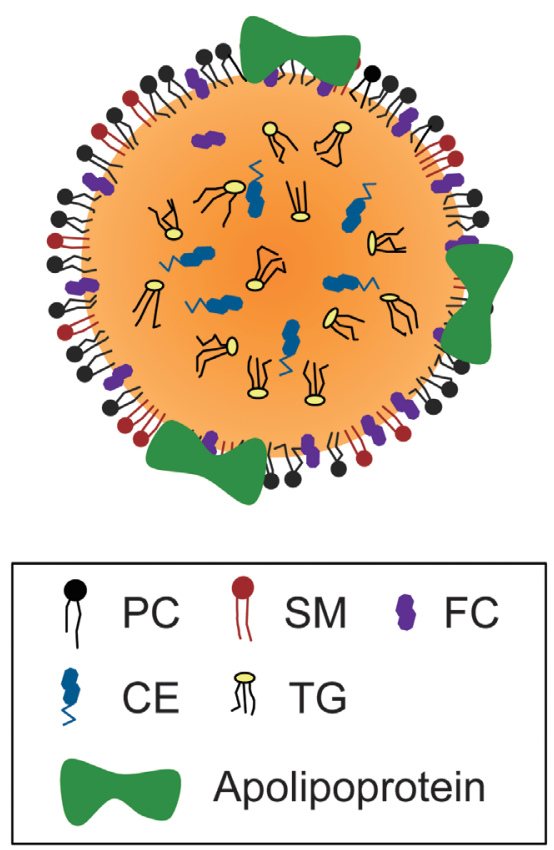

B

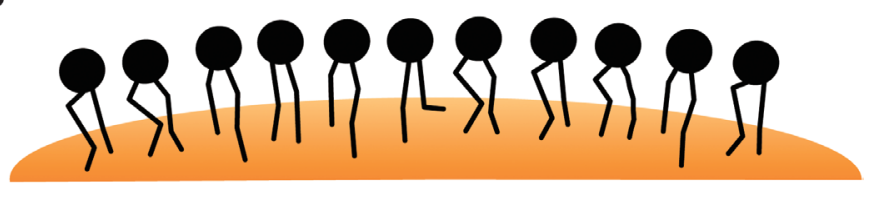

Head group hydration $\downarrow$
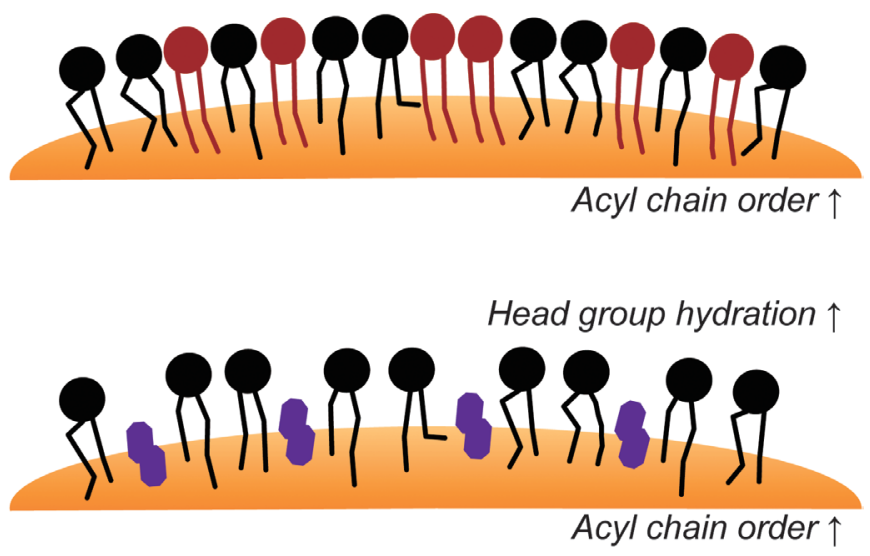

Fig. 1. Schematic Model of Lipoprotein Particle

(A) A lipoprotein particle is composed of a hydrophobic core containing TG and CE and a surface monolayer containing PL, mainly PC and SM, and FC. Apolipoproteins are bound on the particle surface. (B) At the lipoprotein surface, SM molecules increase the acyl chain order and decrease the head group hydration, whereas FC molecules increase the acyl chain order and head group hydration.

CM remnant

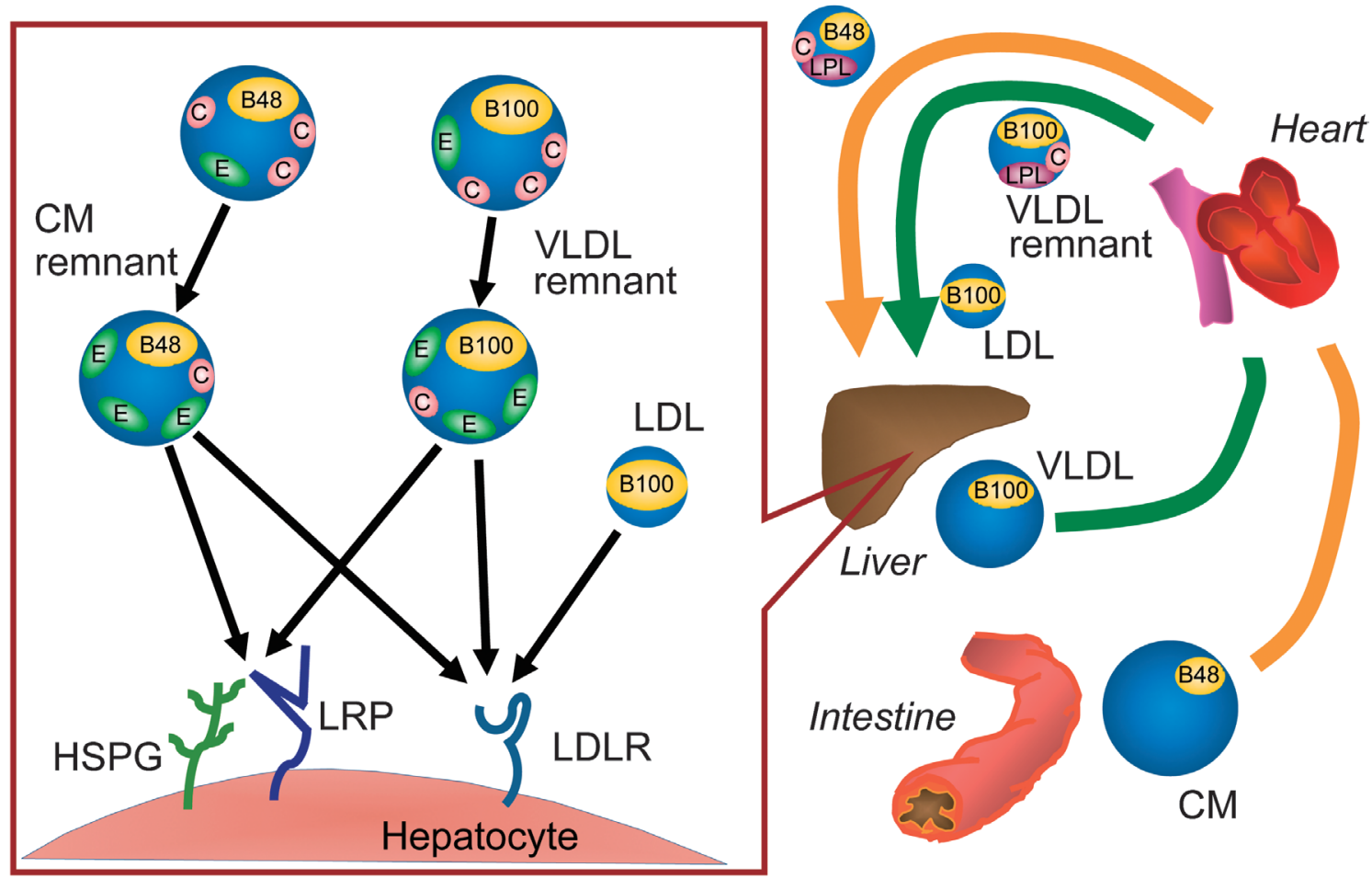

Fig. 2. Metabolism of ApoB-Containing Lipoproteins

CM with apoB-48 and VLDL with apoB-100 are secreted from the intestine and liver, respectively. In the bloodstream, CM remnants are formed by the LPL-mediated lipolysis, which is activated by apoC-II. The lipolysis converts VLDL to VLDL remnants and subsequently to LDL. LDL is taken up into the hepatocytes by LDLR. ApoE-enriched lipoprotein remnants are internalized by the hepatocytes through LDLR or HSPG-LRP pathway. ApoCs prevent the apoE-mediated hepatic uptake of lipoprotein remnants. 


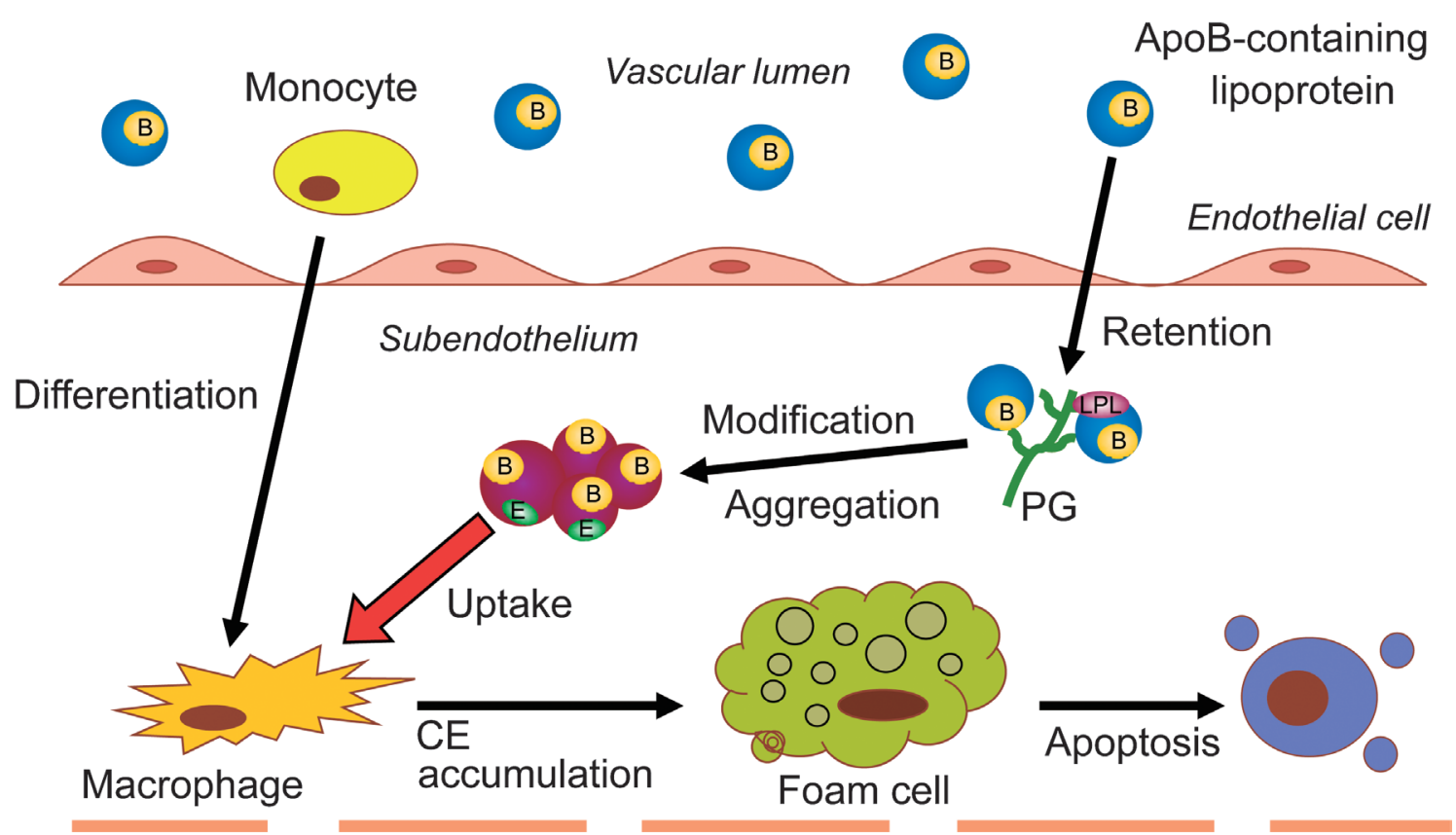

\section{Internal elastic lamina}

Fig. 3. Development of Atherosclerosis Associated with Modified Lipoproteins

Atherosclerosis is initiated by the subendothelial retention of apoB-containing lipoproteins. In the subendothelium, apoB-containing lipoproteins bind to PGs. LPL promotes the binding of lipoproteins to PGs. These lipoproteins are modified by oxidizing agents and enzymes, SMase, phospholipases, LPL and proteases, and are subsequently aggregated. In addition to apoB, these lipoproteins contain apoE. Monocytes enter the subendothelium and then differentiate into macrophages. The uptake of modified lipoproteins by macrophages results in the formation of foam cells storing excess amounts of CE. Furthermore, the accumulation of modified lipoproteins induces the apoptosis of macrophages.

A

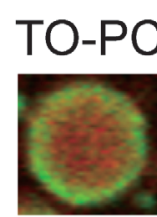

TO-PC/ceramide

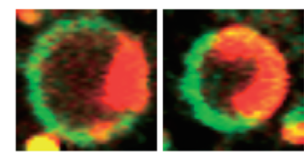

TO-PC/SM + SMase
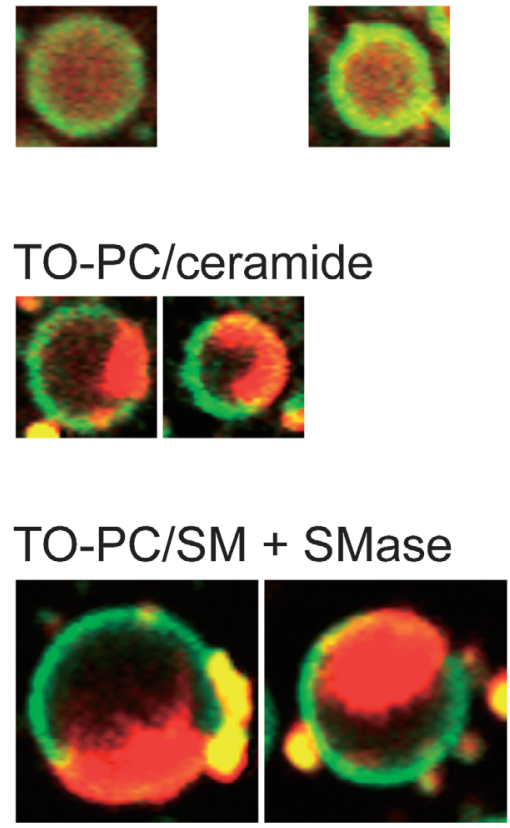

B
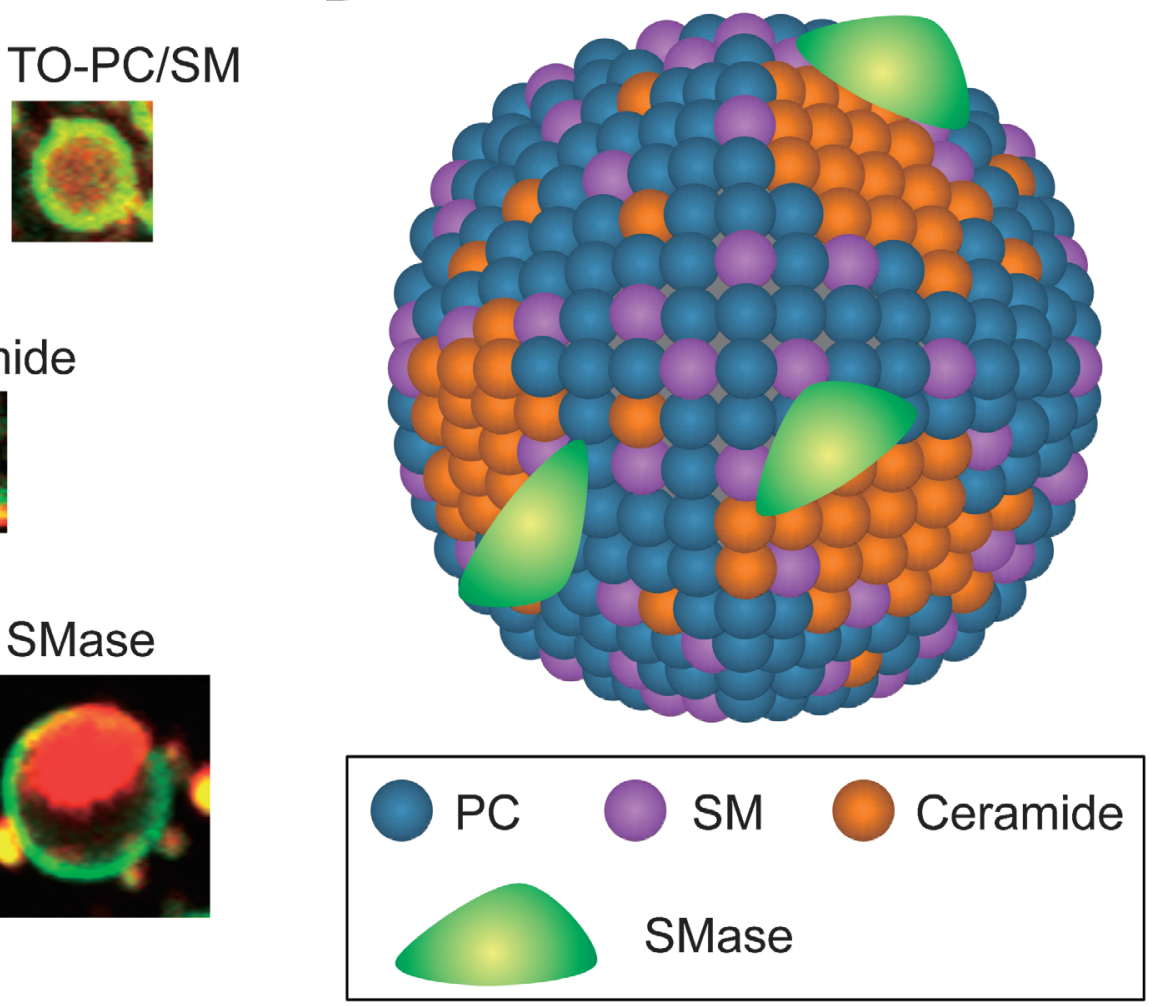

Fig. 4. Formation of Ceramide-Enriched Microdomains in Emulsion Particles

(A) Phase separation in emulsion particles visualized by confocal microscopy. TO-PC, TO-PC/SM and TO-PC/ceramide emulsions contained two fluorescent probes, BODIPY-PC (green) and DiI-C 18 (red). BODIPY-PC favors the fluid phase, whereas DiI- $\mathrm{C}_{18}$ predominantly partitions into the ordered membrane phases. In TO-PC and TO-PC/SM emulsion particles, the uniform distributions of BODIPY-PC in the surface and DiI- $\mathrm{C}_{18}$ in the surface and core were observed. In TO-PC/ceramide emulsion particles, two fluorescent probes were non-uniformly distributed. DiI- $\mathrm{C}_{18}$ fluorescence identified the ceramide-enriched microdomains. Ceramide molecules formed threedimensional, but not in-plane, microdomains extending from core to surface of the particles. The treatment of TO-PC/SM emulsions with SMase led to the formation of ceramide-enriched microdomains and to the fusion of emulsion particles. These images are reproduced from ref. 288. (B) Schematic diagram of ceramide-containing emulsion particles. SMase hydrolyzes SM to ceramide and induces the formation of ceramide-enriched microdomains. 
by lecithin:cholesterol acyltransferase (LCAT). Consequently, CETP mediates the net movement of CE from HDL to VLDL and $\mathrm{CM}$ and that of TG from VLDL and CM to HDL. ${ }^{32)}$ Therefore, LPL activity regulates HDL cholesterol levels by decreasing plasma TG. ${ }^{27)}$ LPL activity is correlated with HDL levels. $^{33)}$ TG-containing HDL are better substrates for HL. Unlike LPL, HL preferentially hydrolyzes lipoprotein PL but also has substantial TG lipase activity. ${ }^{34,35)} \mathrm{HL}$ is synthesized primarily in hepatocytes and is bound mostly to hepatic and endothelial heparan sulfate proteoglycans (HSPGs) in the hepatic sinusoids. ${ }^{36)}$

Glycosylphosphatidylinositol-anchored HDL-binding protein-1 (GPIHBP1) is expressed on the luminal side of the endothelium, binds circulating LPL and TG-rich lipoproteins, and promotes lipolysis. ${ }^{37)}$ Mice lacking GPIHBP1 manifest severe chylomicronemia as a result of defective lipolysis and develop progressive aortic atherosclerosis. ${ }^{38,39)}$ In addition, a homozygous missense mutation in GPIHBP1 causes chylomicronemia in humans. $^{40)}$

2.3. Hepatic Uptake of Lipoproteins The space between the endothelium and hepatocytes is called the space of Disse, which is rich in HSPGs and contains an abundance of apoE secreted by hepatocytes. ${ }^{1)} \mathrm{CM}$ remnants enter the space of Disse through the fenestrated sinusoidal endothelium, which acts as a filter that limits the entry of large $\mathrm{CM}^{41)}$ After entering the space of Disse, lipoprotein remnants become enriched in apoE. The increased amount of apoE enhances the binding of the remnants to HSPGs on the surface of hepatocytes, followed by internalization of the particles through either LDL receptor (LDLR) or LDL receptor-related protein $(\text { LRP })^{1,42)}$ (Fig. 2). HSPGs play a major role in the rapid sequestration of the remnants within the space of Disse, with apoE, HL and LPL serving as ligands. ${ }^{1)}$ HSPGs act as a reservoir for apoE, which is a critical ligand for the clearance of lipoprotein remnants. The ligand-binding region is not present on apoB-48. LPL bound on the remnant particles is carried into the space of Disse. ${ }^{43)}$ About half of the VLDL remnants are taken up by the liver through apoE-mediated pathways, and the remainder are converted to LDL containing only apoB-100. ${ }^{1)}$ ApoB-100-containing lipoproteins are removed from the plasma by LDLR. The liver is the primary site of LDL degradation. LDL particles are generally free of apoE and have lower affinity for LDLR. ${ }^{34)}$

Even in the absence of LDLR, the sequestration of the remnants occurs, followed by slow endocytosis via the HSPGLRP pathway. ${ }^{44)}$ On the other hand, the absence of the LRP is fully compensated for by the upregulation of LDLR in the liver. ${ }^{45}$ Therefore, under normal physiological conditions, LDLR and LRP participate in the internalization of remnant lipoproteins in the liver. However, in the absence of apoE, the sequestration and endocytosis of remnants are extremely restricted.

ApoCs inhibit the apoE-mediated hepatic uptake through the displacement of apoE on these particles or through a direct interaction with apoE. The hepatic uptake of remnant particles is governed by the balance of apoE and apoCs on the particle surface. $^{46)}$

\section{ATHEROSCLEROSIS}

3.1. Subendothelial Retention and Modification of Li- poproteins Atherosclerosis is a multifactorial disorder, and involves many processes, such as lipoprotein retention, lipoprotein modification and aggregation, endothelial alteration, macrophage chemotaxis and foam cell formation, and smooth muscle cell migration and alteration.

Atherosclerosis is initiated by the subendothelial retention of apoB-containing lipoproteins including LDL, lipoprotein remnants, and $\mathrm{Lp}(\mathrm{a})^{47-50)}$ (Fig. 3). The subendothelial deposition of cholesterol is correlated with the level of arterial exposure to cholesterol-rich lipoproteins. ${ }^{47)}$ Even in the absence of other risk factors, elevated levels of lipoproteins containing apoB can drive the development of atherosclerosis in humans and animals. ${ }^{51)}$ LDL-lowering drugs are the most effective therapy against atherothrombotic cardiovascular disease and decrease the probability that apoB-containing lipoproteins will be retained in the subendothelium. ${ }^{49}$

Approximately $85 \%$ of arterial lipoprotein delivery to the subendothelium is estimated to occur via transcytosis, whereas lesser amounts of lipoproteins are delivered via gap junctions or other processes. ${ }^{52)}$ ApoB-containing lipoproteins greater than $70 \mathrm{~nm}$ cannot traverse the endothelium because of the size limitation of transcytotic vesicles. ${ }^{47,53)}$

The dense extracellular matrix of the subendothelium forms an organized tight network and plays a major role in the retention of atherogenic lipoproteins. Subendothelial matrix molecules exist in the extracellular space and on the cell surface in the intima, and mainly consist of proteoglycans (PGs), collagen, and elastin. ${ }^{54)}$ The three major classes of glycosaminoglycans (GAGs) in the vascular system are heparan sulfate (HS), chondroitin sulfate (CS), and dermatan sulfate (DS). ${ }^{55)}$ In particular, PGs containing side chains of CS play a major role in the retention of atherogenic lipoproteins. The interaction between atherogenic lipoproteins and PGs involves an ionic interaction between basic amino acids in apoB or apoE and negatively charged sulfate groups associated with extracellular and cell surface PGs. ${ }^{48,49,54,56,57)}$ Lipoprotein lipids and $\mathrm{PG}$ core proteins also participate in the interaction. ${ }^{49,57)}$ Among CS-containing PGs, biglycan and versican are especially important in the apoB-containing lipoprotein retention within arteries. ${ }^{49,57)}$ In addition, LPL facilitates the binding of apoB-containing lipoproteins to PGs by acting as a bridging molecule. ${ }^{47,49,54)}$ In the extracellular matrix of the arterial intima, LPL is secreted by the intimal macrophages and smooth muscle cells. ${ }^{58,59)}$

In the process of atherogenesis, lipoprotein particles are modified and aggregated in the arterial walls. These modifications to lipoproteins include lipolysis by LPL, sphingomyelinase (SMase) and phospholipases, oxidation with various agents, proteolysis, glycosylation, desialylation, and complexation with PGs. ${ }^{49,54,60)}$ Aggregated lipoproteins have an increased binding affinity for PGs, and their larger size physically prevents their release from the subendothelial space. ${ }^{53,61)}$ SMase induces both aggregation and fusion of lipoprotein particles, but phospholipase $\mathrm{A}_{2}$ induces only aggregation of the particles. ${ }^{61)}$ Oxidation of lipoproteins involves the attack on many constituents, including cholesterol, fatty acids, antioxidants and apoB. ${ }^{62)}$ Lipoproteins isolated from lesions contain lipid oxidation products, ranging from relatively early products, such as cholesteryl linoleate hydroperoxide, hydroxide and ketone, and isoprostanes, to advanced short-chain aldehydes esterified to CE or PL. ${ }^{62)}$ Oxysterols are also elevated 
in the plaque tissues. ${ }^{62)}$ Cathepsins $\mathrm{S}, \mathrm{K}$ and $\mathrm{F}$ are present in the arterial intima and are capable of degrading apoB, which results in enhanced retention of lipoproteins to arterial PGs. ${ }^{63)}$

Another important lipoprotein in lesion development is $\mathrm{Lp}(\mathrm{a})$. $\mathrm{Lp}(\mathrm{a})$ is a form of LDL that is modified in the liver by covalent attachment of apoB to apo(a), a member of the plasminogen gene family. In the subendothelial matrix, fibronectin binds $\mathrm{Lp}$ (a) via the heparin binding domain of fibronectin and the lysine binding sites of apo(a). ${ }^{64)}$ In addition to LDL, Lp(a) is retained in the arterial intima and is modified by the intimal enzymes and agents. ${ }^{54)} \mathrm{Lp}(\mathrm{a})$ is rich in potentially atherogenic oxidized PL. ${ }^{65}$ Lp(a) also has antifibrinolytic effects, which enhances its atherogenicity. ${ }^{66)}$

The size of human LDL can be separated into two phenotypes: large buoyant LDL (1.019-1.043 g/mL) and sdLDL $(1.044-1.063 \mathrm{~g} / \mathrm{mL})$. SdLDL is characterized as $18.0-20.5 \mathrm{~nm}$ in diameter. ${ }^{11)}$ SdLDL is more atherogenic than large buoyant LDL. SdLDL particles have higher affinity for PGs than large buoyant LDL particles. ${ }^{67)}$

3.2. Foam Cell Formation The perturbation of the arterial endothelium leads to the upregulation of cell adhesion molecule. ${ }^{68)}$ The blood-borne monocytes enter susceptible areas of the subendothelium of large and medium-sized arteries and then differentiate into macrophages, which is one of the key cellular events during atherogenesis ${ }^{69)}$ (Fig. 3). Smooth muscle cells also migrate into the intima. ${ }^{70)}$ The lipoprotein modification in the arterial wall leads to the macrophage chemotaxis. ${ }^{71)}$

The lesions are initiated by the formation of fatty streaks in the artery, when macrophages in the vessel wall take up lipoproteins from the subendothelial space. ${ }^{72)}$ Accumulation of excess cholesterol derived from lipoproteins in arterial macrophages is one of the critical steps in the progression of atherosclerosis. The uptake of matrix-retained lipoproteins by macrophages and smooth muscle cells leads to the formation of foam cells storing a large amount of CE. ${ }^{50,70,73)}$ However, native LDL is incapable of generating foam cells from macrophages. $^{74)}$

The uptake of modified lipoproteins by macrophages is a complex process involving receptor-mediated endocytosis and phagocytosis. ${ }^{75,76)}$ Macrophages express LDLR as well as LRP. In addition, the apoB-48 receptor on macrophages is implicated in the apoE-independent pathway for the uptake of TG-rich lipoproteins and recognizes apoB-48 and apoB-100. ${ }^{77)}$ Furthermore, macrophages express several different scavenger receptors that recognize modified lipoproteins. ${ }^{62,78)}$ Aggregated lipoproteins are taken up via phagocytosis, by LRP, by scavenger receptors, and through patocytosis. ${ }^{75,79-81)}$ In patocytosis, the aggregated LDL induces and enters surface-connected compartments. ${ }^{80}$ ) Oxidized LDL (oxLDL) is a ligand for scavenger receptors expressed on the macrophage surface, including class A scavenger receptor type I/II and CD36. ${ }^{62,78)}$ These scavenger receptors are multifunctional and interact with several structurally different ligands. ${ }^{62,78)}$

LDL with native apoB-100 enters macrophages by LDLR and is a poor inducer of foam cell formation. ${ }^{74)}$ After LDL particles are taken up by macrophages and delivered to the lysosomes, CE is hydrolyzed to FC by lysosomal acid lipase. The resulting FC is transferred to the ER and reesterified by acyl-CoA:cholesterol acyltransferase (ACAT), which is localized in the ER membranes. ${ }^{82)}$ Niemann-Pick C1 (NPC1) pro- tein on the lysosomal membranes accepts FC from NiemannPick C2 (NPC2), a soluble luminal protein of lysosomes, and then mediates FC trafficking to the ER membranes or plasma membranes, depending on the vesicular transport or oxysterolbinding protein-related proteins. ${ }^{83,84)}$ In the hydrophobic handoff model, the patches of amino acids on NPC1 and NPC2 interact so that the transfer of FC from NPC2 to NPC1 is achieved. ${ }^{83,84)}$

Lysosomal FC predominantly distributes to the plasma membrane, where FC is available for the efflux mediated by ATP-binding cassette transporter A1 (ABCA1) and apoA-I leading to the formation of HDL. After reaching a threshold level, the cellular FC is esterified by ACAT, which leads to the accumulation of intracellular $\mathrm{CE} .^{81)} \mathrm{CE}$ accumulates in cytoplasmic droplets during the early fatty streak stage of atherosclerosis. ${ }^{62)}$ However, CE also increasingly accumulates within large swollen lysosomes of foam cells in the fibrous plaque. $^{62)}$

3.3. Apoptosis of Macrophages Numerous studies have identified apoptosis as a prominent feature of atherosclerosis. ${ }^{85,86)}$ All cell types present in atherosclerotic plaques, including endothelial cells, smooth muscle cells, lymphocytes and macrophages, undergo apoptosis. The accumulation of modified lipoproteins induces the apoptosis of monocytederived macrophages ${ }^{85-87)}$ (Fig. 3). In early lesions, where phagocytic clearance of apoptotic cells appears to be efficient, macrophage apoptosis may decrease macrophage burden and slows lesion progression. ${ }^{86,88,89)}$ On the other hand, macrophage apoptosis in late lesions causes necrotic core formation, which promotes inflammation, plaque rupture, and thrombosis. ${ }^{86)}$ The membranes of the apoptotic cells are eventually disrupted, leading to the release of intracellular contents and to the inflammatory responses. ${ }^{86)}$ Therefore, the macrophage apoptosis is a crucial determinant of lesion development.

Macrophages in advanced atherosclerotic lesions accumulate large amounts of FC, which is a potent inducer of apoptosis. ${ }^{82,86,87)}$ Macrophages have several mechanisms to prevent the accumulation of excess FC, such as cholesterol esterification by ACAT, efflux of cellular FC by ABCA1, and downregulation of LDLR and cholesterol biosynthetic enzymes. ${ }^{82}$ ) In atherosclerotic lesions, however, these mechanisms are often ineffective, which results in the accumulation of excess FC in macrophages. High FC/PL ratio in cellular membranes alters the functions of integral membrane proteins due to high membrane rigidity. ${ }^{82)}$ The PL synthesis also increases to offset the harmful effects of excess FC, and, as a consequence, the PL-containing whorl-like membrane structures exist in the lesional macrophages. ${ }^{82)}$

The abnormal enrichment of the plasma membrane with FC results in the dysfunction of membrane-associated enzymes and transporters and in subsequent macrophage death. ${ }^{90}$ On the other hand, the FC accumulation in the ER membrane induces the unfolded protein response, leading to an apoptotic response in the macrophages. ${ }^{91)}$ The ER membrane is normally FC poor and highly fluid. ${ }^{87)}$ Needle-shaped cholesterol crystals typically form in the extracellular regions of advanced atherosclerotic lesions. ${ }^{82)}$ Intracellular cholesterol crystals are also present in the atherosclerotic lesions and physically disrupt the intracellular structures. ${ }^{82,92)}$ In addition, excess intracellular FC accumulation promotes the generation of cytotoxic oxysterols. ${ }^{82)}$ The macrophage apoptosis induced by oxLDL is 
indeed mediated by oxysterols. ${ }^{93)}$ Oxysterols induce apoptosis through various mechanisms including lysosomal rupture, elevation in intracellular calcium, and the mitochondrial apoptotic pathway. ${ }^{94)}$

\section{LIPOPROTEIN-ASSOCIATED PROTEINS}

4.1. ApoB Human apoB-100, a 4536-amino acidsecretory glycoprotein, has a particularly critical role in the assembly of VLDL in the liver. ${ }^{14)}$ A unique mRNA editing in the small intestine generates a truncated form of apoB corresponding to its N-terminal 48\% (apoB-48), which directs the formation of CM. ${ }^{95)}$ ApoB-100 plays a particular role in maintaining the structural integrity of lipoprotein particles and in controlling their interaction with LDLR. ${ }^{96)}$ An LDL particle contains a single apoB-100 molecule together with about 3000 lipid molecules. Sixteen $N$-glycosylation sites in apoB-100 are glycosylated with high-mannose and complex forms of oligosaccharides. ${ }^{97,98)}$ ApoB is highly insoluble in aqueous solutions and remains at the lipoprotein particle throughout its metabolism. From the circular dichroism (CD) spectra of LDL, the secondary structure of apoB-100 is characterized by a large content of $\alpha$-helix (ca. 50\%) and smaller amounts of $\beta$-sheet (ca. 11\%), $\beta$-turn (ca. 27\%) and random coil (ca. 13\%). ${ }^{99)}$ The lipid-binding property of apoB is ascribed to a series of amphipathic $\alpha$-helical and $\beta$-strand domains arranged in the following order: $\mathrm{NH}_{2}-\beta \alpha_{1}-\beta_{1}-\alpha_{2}-\beta_{2}-\alpha_{3}-\mathrm{COOH}{ }^{2)}$ The $\beta \alpha_{1}$ domain represents a globular region. ${ }^{2}$ The amphipathic $\alpha$-helices of the $\alpha_{2}$ and $\alpha_{3}$ domains are similar to those found in exchangeable apolipoproteins. ${ }^{2}$ ) The amphipathic $\beta$-strands are the anchors keeping apoB bound to the lipoprotein surface. ${ }^{100,101)}$ The portion of apoB-100 that forms amphipathic $\beta$-sheets interacts directly with the lipid core. ${ }^{14)}$ The irreversibly lipidassociating $\beta$-sheet regions of apoB-100 are key structural areas for the integrity of LDL particles.

The first $89 \%$ of apoB-100 enwraps the LDL particle like a thick ribbon, completing the encirclement by approximately amino acid residue 4050, the junction of the $\beta_{2}$ and the $\alpha_{3}$ domains. ${ }^{102)}$ There is a kink in the ribbon beginning almost halfway along its length at the start of the $\alpha_{2}$ domain. ${ }^{102)}$ The C-terminal $11 \%$ of apoB-100, $\alpha_{3}$ domain, constitutes the bowlike structure of about 480 residues beginning at residue 4050 , which stretches back and then crosses over the ribbon between residues 3000 and $3500 .^{102)}$

ApoB-containing lipoprotein assembly requires the PL transfer activity of MTP. ${ }^{103)}$ In the absence of MTP, apoB folds incorrectly and undergoes proteasomal degradation. In the setting of apoB deficiency, although the smooth ER contains lipid droplets, no droplets are observed in the Golgi and the intercellular space. ${ }^{13)}$ When apoB synthesis occurs, lipoprotein particles exist in the Golgi and the intercellular space. ApoB is required for the transport of lipoproteins from the ER to the Golgi, and its structure may play an important role in the lipoprotein secretion.

ApoB-100 is responsible for the binding to LDLR but not other members of the LDLR family. ${ }^{2,104)}$ In the genetic disorder familial defective apoB-100, high levels of LDL accumulate in the circulation, which leads to hypercholesterolemia and premature atherosclerosis. ${ }^{105)}$ Familial defective apoB-100 is caused by a mutation of apo-B100 (R3500Q), which disrupts the binding of LDL to LDLR. ${ }^{105)}$ Another mutation R3531C is also associated with a decrease in LDLR binding. ${ }^{106)}$ LDLR binding sites exist in the $\alpha_{3}$ domain of apoB-100. ${ }^{107)}$ Three long positively charged amphipathic $\alpha$-helices, residues 3147-3157, 3170-3208, and 3359-3367, are termed site A, site $\mathrm{C}$, and site $\mathrm{B}$, respectively. ${ }^{2)}$ Site $\mathrm{B}$ is the domain interacting with LDLR, whereas site A is not the primary LDLR binding site. ${ }^{2,108)} \operatorname{Arg} 3500$ is not directly involved in receptor binding, although the R3500Q mutation of apoB-100 leads to inability of the LDL particles to interact with LDLR. ${ }^{108)}$ However, the removal of $20 \%$ C-terminal domain in the R3500Q mutant results in the normal receptor-binding activity, indicating that the carboxyl-terminal $20 \%$ of apo-B100 is necessary for the R3500Q mutation to disrupt receptor binding. ${ }^{108)}$ The R3500Q mutation has been proposed to induce a conformational change in the C-terminal tail. ${ }^{56)}$

ApoB-48 is capable of binding PGs despite lacking site B. ${ }^{109)}$ In addition to LDLR binding, apoB-100 contains at least eight potential PG-binding sites. ${ }^{60}$ The binding of LDL to PGs is mediated by ionic interactions between the negatively charged sulfate and carboxyl groups of the GAGs and the positively charged lysine and arginine residues in apoB-100. ${ }^{54)}$ The binding of LDL particles to GAGs is severely impaired by the mutation of Lys3363 of apoB-100. ${ }^{56)}$ Based on the number of available binding sites, the affinity of apoB-48 for PGs is greater than that of apoB-100, suggesting that apoB-100 masks the high-affinity sites present on apoB-48. ${ }^{47,110)}$

4.2. ApoE ApoE, a 299-amino acid plasma apolipoprotein, is a ligand for LDLR and LRP, and binds to cell surface HSPGs. ${ }^{111)}$ ApoE has seven amphipathic helical segments that are responsible for lipid binding. ${ }^{12)}$ Based on the binding model of apolipoproteins, the apolipoprotein helices are predicted to deeply insert into the surface layers, such that the amphipathic helices are buried within the hydrophobic interior of PL monolayers. ${ }^{113)}$ Apo $\mathrm{E}$ is tetrameric in aqueous solution but monomeric on the lipid particle surfaces. ${ }^{114)}$ ApoE contains two independently folded domains, the 22-kDa N-terminal domain and 10-kDa C-terminal domain. ${ }^{111)}$ The C-terminal domain has a high affinity for lipid and is responsible for lipoprotein binding and preference. ${ }^{115)}$ The N-terminal domain exists in the lipid-free state as a four-helix bundle and contains the LDL receptor-binding region. ${ }^{116)}$ The cluster of arginine and lysine residues located between residues 136-158 represents the binding site for LDLR. The segment comprising the receptor-binding portion of apoE (residues 130-149) interacts with ligand-binding clusters of LRP. ${ }^{117,118)}$ Both domains of apoE contain heparin-binding sites, but the N-terminal site plays a dominant role in the binding to heparin. ${ }^{119)}$ The cluster of positively charged amino acids between residues 136-150 is also involved in the heparin interaction. The four-helix bundle in the N-terminal domain undergoes a conformational opening upon lipid binding, leading to the receptor-active conformation of apoE. ${ }^{111,120)}$ In this conformation, the positive electrostatic potential in the receptor-binding region of apoE is enhanced. ${ }^{121,122)}$ The leucine zipper motif confers stability to the helix bundle conformation of the N-terminal domain, which serves to maintain apoE in a receptor-inactive state. ${ }^{123)}$ It has been proposed that apoCs and/or lipid composition induce conformational alteration of the $\mathrm{N}$-terminal domain of apoE and modulate the receptor binding properties, between an open lipid-bound receptor-active state and a globular receptor-inactive state. ${ }^{124)}$ 
The liver produces the vast majority of plasma apoE, and apoE promotes the internalization of TG-rich lipoprotein remnants by hepatocytes. CM contains essentially no apoE, whereas their remnants acquire apoE from other lipoprotein classes. ${ }^{112)}$ ApoE is lost from the surface of LDL particle. Patients lacking apoE accumulate remnant lipoproteins. ${ }^{125)}$ ApoE knockout mice have high levels of plasma cholesterol and readily develop atherosclerosis. ${ }^{126,127)}$ ApoE knockout mice contain large amounts of circulating apoB-48-containing lipoproteins that cannot interact with LDLR and LRP.') Catabolism of these lipoproteins is highly dependent on the HSPGmediated removal pathways.

Within atherosclerotic lesions, lipoproteins contain apoE in addition to apoB-100. ${ }^{128)}$ Lipoprotein remnants with apoE are avidly taken up by and markedly stimulate the CE accumulation in macrophages. ${ }^{129)}$ In the lesions, most of the apoE molecules are synthesized locally by resident macrophages. ${ }^{130)}$ Additionally, apoE directly modifies macrophage-mediated immune responses that contribute to atherosclerosis. ${ }^{68)}$

The genetic disease type III hyperlipoproteinemia is characterized by impaired clearance of lipoprotein remnants, as a result of various mutant forms of apoE that are defective in binding to lipoprotein receptors. ${ }^{1)}$ ApoE exists as one of three predominant isoforms. ${ }^{12,124)}$ ApoE3 isoform is the most abundant isoform and possesses a single cysteine residue at position 112 with arginine at position 158. ApoE4 isoform contains an arginine at position 112, while apoE2 isoform has cysteines at both positions 112 and 158. Isoforms apoE3 and apoE4 bind to hepatic lipoprotein receptors with high affinity, whereas apoE2 binds only weakly. ${ }^{131)}$ The LDLR-binding activity of apoE2 isoform is dramatically reduced (less than $2 \%$ of normal apoE3 activity), which is associated with type III hyperlipoproteinemia. ${ }^{132)}$ The altered salt bridge interaction in apoE2 induces the deformation of the receptor-binding region. ${ }^{133)}$ Nevertheless, the majority of apoE2 homozygotes do not exhibit hyperlipidemia or significant accumulation of remnant lipoproteins. ${ }^{1)}$ ApoE2 has significant HSPG-binding activity (50-90\% of normal apoE3 activity). ${ }^{134)}$ ApoE also plays essential roles in the transport of lipids in the nervous system. ${ }^{1)}$ ApoE4 isoform is known to be a risk factor for Alzheimer's disease. ${ }^{135,136)}$

ApoCs inhibit the apoE-dependent recognition of TG-rich lipoproteins by LDLR and LRP. ${ }^{137,138)}$ The apoE-mediated hepatic uptake of plasma lipoproteins is controlled by the ratio of apoE to apoCs rather than the absolute apoE content. ${ }^{46)}$

At high concentrations, apoE leads to hypertriglyceridemia. ${ }^{139,140)}$ The apoE content is inversely correlated with the LPL-mediated lipolysis rate of VLDL in vitro. ${ }^{141)}$ ApoE efficiently inhibited the LPL-mediated lipolysis of TG-rich emulsions in vivo and in vitro. ${ }^{142)}$

4.3. ApoC-I ApoC-I is primarily expressed in the liver and consists of 57 amino acid residues. ${ }^{46)}$ ApoC-I residues 7-24 and 35-53 are important for the binding to lipoproteins and adopt well-defined amphipathic helices with distinct hydrophobic and hydrophilic faces. ${ }^{143}$ ApoC-I has inhibitory effects on the LPL activity and on the lipoprotein binding to LDLR and LRP. ${ }^{46,144)}$ Among apoCs, apoC-I is the most potent inhibitor for the apoE-mediated binding of lipoprotein remnants to LRP. ${ }^{145)}$ ApoC-I displaces apoE from TG-rich lipoproteins, and directly interferes with their hepatic clearance. ${ }^{46)}$ In addition to the displacement of apoE from the particles,
apoC-I binding may induce a change in the conformation of apoE bound on the particles and abolish the ability of apoE to interact with LRP. ApoC-I activates the cholesterol esterification by LCAT to a lesser extent than apoA-I, the most powerful activator. ${ }^{146)}$ On the other hand, apoC-I is an inhibitor of CETP. ${ }^{147,148)}$

Transgenic mice overexpressing human apoC-I exhibit elevated levels of cholesterol and TG owing to the accumulation of cholesterol-enriched VLDL, VLDL remnants, and LDL. ${ }^{149,150)}$ In human apoC-I-transgenic mice, the elevated lipid levels are primarily associated with decreased uptake of apoB-containing lipoproteins by the liver rather than with disturbed lipolysis of lipoproteins. ${ }^{149,150)}$ Surprisingly, ApoC1knockout mice show normal serum lipid levels on a chow diet. $^{151)}$

4.4. ApoC-II ApoC-II, a 79-amino acid protein, is mainly expressed in the liver and intestine and is an essential activator of LPL. ApoC-II contains three $\alpha$-helices spanning approximately residues $16-38,45-57$, and $65-74 .^{152)}$ The structures of apoC-II involved in lipid interactions reside at the $\mathrm{N}$ terminus (residues 1-51). ${ }^{46)}$ The helical structure close to the C-terminal end of apoC-II is important for the activation of LPL. ${ }^{153)}$ ApoC-II may bind directly to LPL and activate LPL after binding of LPL to the surface of TG-rich lipoproteins. ${ }^{46)}$ The lipid-binding domain of apoC-II is required for the stimulation of LPL activity. ${ }^{154)}$ At high protein levels, however, apoC-II inhibits LPL activity. ${ }^{46)}$ ApoC-II also has an inhibitory effect on the HL-mediated lipolysis to a lesser extent than apoC-III. ${ }^{155)}$ Both apoC-II and apoC-III inhibit LCAT activity, presumably due to the displacement of the activating apolipoproteins from the lipoprotein surface. ${ }^{156)}$

Genetic deficiency of apoC-II causes severe hyperchylomicronemia. ${ }^{27,46)}$ Patients with genetic defects in apoC-II display high circulating levels of TG. ${ }^{157,158)}$ Remarkably, transgenic mice overexpressing human apoC-II show accumulation of TG-rich VLDL particles in the circulation. ${ }^{159)}$ The high levels of apoC-II inhibit the lipolysis of VLDL and/or the uptake of the VLDL particles by the liver.

4.5. ApoC-III ApoC-III is a 79-amino acid glycoprotein synthesized mainly in the liver and to a minor extent in the intestine as a component of chylomicrons, VLDL, LDL and HDL. ${ }^{111)}$ In normotriglyceridemic subjects, apoC-III is associated primarily with HDL, whereas there is redistribution of apoC-III to chylomicrons and VLDL in the postprandial state and hypertriglyceridemia. ${ }^{160,161)}$ ApoC-III consists of two helical domains. The N-terminal domain of apoC-III is important in the modulation of LPL activity, and the binding of apoC-III to surface PL is mediated by the C-terminal helix. ${ }^{46,162)}$ In the three-dimensional NMR structure of apoC-III in complex with sodium dodecyl sulfate (SDS) micelles, 6-10-residue amphipathic helices wrap around the micelle surface, three positively charged residues line the polar faces of helices 1 and 2 , and an array of negatively charged residues lines the polar faces of helices 4 and 5 and the adjacent flexible loop. ${ }^{163)}$ ApoC-III molecules are separated into three isoforms that differ in their degree of $O$-linked sialylation at the threonine residue in position $74 .^{46}$ The intracellular glycosylation of apoC-III is not necessary for its secretion from cells and ability to bind plasma lipoproteins. ${ }^{164)}$

ApoC-III plays a role as a potential inhibitor of the LPLmediated lipolysis, both by a direct interaction with LPL and 
by interfering with lipoprotein binding to the cell surface GAG matrix where lipolytic enzymes reside. ${ }^{144)}$ The mechanism of apoC-III-LPL interaction is accounted for by the lipid-binding part of molecules or attributed to protein-protein interactions that are independent of lipid binding. ${ }^{162,165)}$ ApoCIII also inhibits HL. ${ }^{155}$ )

ApoC-III completely abolishes the apoB-100-mediated binding of lipoproteins to LDLR, suggesting that this inhibitory action of apoC-III on lipoprotein binding is due to a masking of the receptor domain of apoB-100 by apoC-III. ${ }^{166)}$ Increased levels of apoC-III on the lipoprotein particles displace apoE, which may result in decreased remnant clearance. ${ }^{167)}$

The human apoC-III gene is located in a gene cluster together with the apoA-I and apoA-IV genes on the long arm of chromosome 11. ${ }^{168)}$ ApoC-III deficiency is usually associated with apoA-I and apoA-IV deficiency, making it difficult to estimate the respective contributions of these deficiencies. ${ }^{169,170)}$ Patients with hereditary deficiency of apoC-III and apoA-I had low plasma TG and accelerated clearance of both $\mathrm{CM}$ and VLDL. ${ }^{171,172)}$ Homozygosity of the A641C allele in the apoCIII gene promoter is associated with significantly lower serum levels of apoC-III, ${ }^{173)}$ whereas the variant alleles in the apoCIII gene promoter (C482T and T455C) cause a 30\% increase in the fasting plasma apoC-III concentration compared with the wild-type homozygotes. ${ }^{174)}$

ApoC-III in VLDL and LDL is an independent risk factor for coronary heart disease. ${ }^{175-177)}$ A high concentration of apoC-III-containing VLDL is associated with the delayed catabolism of TG in VLDL and hypertriglyceridemia. ${ }^{178,179)}$ ApoC-III enhances the conversion from buoyant LDL to dense LDL. ${ }^{180,181)}$ ApoC-III deficiency (by ca. 50\% of normal levels) confers a favorable lipid profile and reduced subclinical coronary artery atherosclerosis. ${ }^{182)}$ The polymorphisms in the apoC-III gene promoter are associated with plasma apoC-III concentration, plasma TG concentration, lipoprotein profile, cardiovascular health, nonalcoholic fatty liver disease, insulin sensitivity, and longevity. ${ }^{173,174)}$ Human apoC-III transgenic mice exhibit markedly elevated levels of CM and VLDL TG. ${ }^{183)}$ In addition, a synergistic interaction between the human apoC-III transgene and LDLR defects produces large quantities of VLDL and LDL and enhances the development of atherosclerotic lesions in mice. ${ }^{184)}$ ApoC-III delays the metabolism of TG-rich lipoproteins by inhibiting LPL activity and apoE-dependent hepatic uptake, which may increase the probability of cholesterol deposition of lipoprotein particles in the vessel wall. ${ }^{177,178)}$

4.6. ApoA-I ApoA-I, a 243-amino acid protein, is the major apolipoprotein component of HDL, serving as an activator of LCAT and functioning as an acceptor of cell membrane FC in the reverse cholesterol transport pathway. ${ }^{111,185)}$ ApoA-I mediates the formation of nascent HDL particles from cellular FC and PL through the interaction with the cell surface transporter ABCA1. ${ }^{186,187)}$ The majority of apoA-I is secreted from the liver. ApoA-I molecules are also accommodated in CM. ApoA-I is comprised of an N-terminal domain (residues 1-43) and the remaining region containing eight 22- and two 11-amino acid amphipathic $\alpha$-helices. ${ }^{111)}$ ApoA-I may initially bind to a lipid surface through amphipathic $\alpha$-helices in the $\mathrm{C}$ terminal domain, followed by opening of the helix bundle in the N-terminal domain. ${ }^{188)}$

4.7. LPL LPL catalyzes the hydrolysis of plasma TG, diglycerides, PC, and phosphatidylethanolamine transported in CM and VLDL. ${ }^{189)}$ The hydrolyzing activity of LPL toward PL is much lower than that toward TG. ${ }^{190)}$ LPL is synthesized primarily in adipose and skeletal muscle. LPL is transported to the endothelial surface and is bound to HSPGs. ${ }^{31)}$ LPL binding to endothelial cells is not a static situation. Some LPL dissociates from the cells, and some LPL is internalized and recycled to the cell surface. ${ }^{191)}$ LPL is also expressed in the nervous system, adrenals, macrophages, proximal tubules of the kidneys, pancreatic islet cells, and lungs. ${ }^{192)}$ The LPL activity in pancreatic islet cells is related to insulin secretion and lipotoxicity. ${ }^{193)}$

The cDNA of LPL codes for a 475-amino-acid protein including a 27-amino-acid signal peptide. The catalytic center is formed by three amino acids: Ser132, Asp156 and His241. ${ }^{192)}$ The enzymatic activity of LPL is localized within its Nterminal domain, and the C-terminal domain of LPL contains binding sites for lipoproteins and for specific cell-surface receptors, including HSPGs and members of the LDLR family. ${ }^{194-197)}$ LPL can enhance the binding and uptake of several classes of lipoproteins through bridging between the lipoproteins and HSPGs. ${ }^{194,195)}$ Furthermore, LPL enhances the uptake of remnants partially mediated by the ability of LPL to directly bind to LRP and LDLR. ${ }^{196,197)}$ The hydrolytic activity of LPL is not required for this bridging function. ${ }^{195,197)}$

For maximal rates of catalysis, LPL requires apoC-II. ${ }^{189)}$ ApoC-II does not increase the binding of LPL to a lipid surface. ${ }^{189)}$ LPL is capable of hydrolyzing TG present in the PL monolayer. ${ }^{198)}$ LPL may interact with the head group region of PL rather than with the hydrophobic interior of the surface monolayers. ${ }^{199)}$ LPL binds to the lipid surface without marked changes in the surface structure, suggesting superficial binding of LPL to the PL surface. ${ }^{200)}$

In the rare autosomal recessive disorder of familial LPL deficiency (type I hyperlipoproteinemia), the near absence of LPL activity results in fasting hypertriglyceridemia. ${ }^{189)}$ Heterozygotes for LPL deficiency have abnormalities in postprandial lipemia despite relatively normal fasting TG. ${ }^{27)}$ There are several polymorphisms of LPL that are associated with hypertriglyceridemia. ${ }^{192,201)}$

The LPL activity is found in greater amounts in the atherosclerotic lesions than in the normal arteries. ${ }^{27)}$ In the medium and large arteries, LPL is present on the luminal endothelial surface and in the macrophage-rich areas within the plaque. LPL is expressed by macrophages within the vessel wall. Increased LPL activity in the arterial wall is correlated with increased areas of lipid deposition and increased atherosclerotic lesion formation. ${ }^{8)}$ LPL activity in mouse macrophages is correlated with their propensity to develop atherosclerosis. $^{202)}$ Macrophage-derived LPL shows a proatherogenic role in LDLR-deficient mice. ${ }^{203)}$ LPL forms macromolecular aggregates by simultaneously binding to both matrix PGs and apoB-containing lipoproteins, which increases their retention by subendothelial matrix and uptake by cells. ${ }^{204)}$

\section{LIPOPROTEIN RECEPTORS}

5.1. LDLR LDLR, a $160 \mathrm{kDa}$ protein, plays a major role in plasma LDL uptake and is expressed in all mammalian cell types. ${ }^{205)}$ LDLR binds lipoproteins containing apoB-100 and/ or apoE. ${ }^{131)}$ LDLR contains seven imperfect, ligand-binding 
repeats located at the N-terminus. ${ }^{206)}$ Each repeat is $c a .40$ amino acids in length, binds calcium and is characterized by an abundance of cysteines and negatively charged aspartate and glutamate residues.

Familial hypercholesterolemia is a genetic defect of LDLR. In patients with familial hypercholesterolemia, poor removal of LDL particles from the circulation and LDL accumulation results in an increase in plasma cholesterol concentrations. Nevertheless, lipoprotein remnants are cleared rather normally in the patients. ${ }^{1)}$

Proprotein convertase subtilisin/kexin type 9 (PCSK9) promotes the degradation of hepatic LDLR and reduces the efficiency of endocytic function. ${ }^{49,207)}$ Secreted PCSK9 decreases the number of LDLR in mice hepatocytes. Sequence variations in PCSK9 lead to decreased plasma LDL and result in a substantial reduction in the incidence of atherosclerotic heart disease. ${ }^{208)}$ In heterozygous familial hypercholesterolemia, two monoclonal antibodies against PCSK9, alirocumab and evolocumab, diminish plasma LDL cholesterol, apoB and Lp(a). ${ }^{209,210)}$ Upregulation of LDLR may also increase the plasma clearance of Lp(a).

5.2. LRP LRP is a $600 \mathrm{kDa}$ multiligand receptor, which is expressed strongly in hepatocytes and binds apoEcontaining remnant lipoproteins and other proteins. ${ }^{211)}$ LRP has multiple ligands, including apoE, HL, LPL, and activated $\alpha_{2}$-macroglobulin. ${ }^{1)}$ LRP recognizes apoE but not apoB-100. The ability of LRP to bind numerous structurally distinct ligands with high affinity arises from the ligand-binding sites with unique contour surface and charge distribution. ${ }^{211)}$ LRP is structurally similar to other members of the LDLR gene family. LRP consists of five common structural units, ligandbinding type cysteine-rich repeats, epidermal growth factor receptor-like cysteine-rich repeats, YWTD domains, a single membrane-spanning segment, and a cytoplasmic tail. ${ }^{211)}$

The receptor-associated protein, a $39 \mathrm{kDa}$ protein, exists in the ER and is a specific inhibitor of ligand binding to LRP. ${ }^{211)}$ In receptor-associated protein knockout mice, the total amount of LRP present in the liver is reduced by $80 \%{ }^{212}$ which is caused by the aggregation of LRP in the ER and subsequent intracellular degradation. ${ }^{213)}$ LRP also serves as the receptor for $\alpha_{2}$-macroglobulin. The activated $\alpha_{2}$-macroglobulin can compete with lipoprotein remnants for LRP binding. ${ }^{1)}$

LRP is also present in macrophages and vascular smooth muscle cells from atherosclerotic lesions and normal vessels. $^{214,215)}$ LRP, contrary to LDLR, is not regulated by intracellular cholesterol.

5.3. HSPG HSPGs are members of the family of PGs, which are components of cell membranes and extracellular matrix. ${ }^{1,27,55)}$ The two major parts of the PG molecule are GAGs and core proteins. HSPGs are polyanionic macromolecules that contain a core protein with multiple HS chains covalently attached. In the liver, the major core proteins are syndecans, although glypican, betaglycan and perlecan are also present. ${ }^{216)} \mathrm{HS}$ is a polymer composed of repeating disaccharide units of a hexuronic acid (either glucuronic acid or iduronic acid) and glucosamine. The glucosamine residues are either $N$-acetylated or $N$-sulfated, and both hexuronate and glucosamine residues are $O$-sulfated in varying positions. ${ }^{217)}$ Heparin differs from HS in the extent of $\mathrm{N}$-acetylation, $\mathrm{N}$ sulfation and $O$-sulfation, and in the content of iduronate. ${ }^{27)}$ Hepatic HSPGs are especially diverse, highly sulfated, and rich in heparin-like domains. ${ }^{1)}$

The major HSPG in the subendothelial matrix is perlecan. ${ }^{218)}$ The contents of CSPGs and DSPGs are increased in atherosclerosis. In contrast, HSPGs negatively correlate with human atherosclerosis, aging and diabetes. ${ }^{219,220)}$ The amount of cholesterol accumulated in the lesion is inversely correlated to the amount of HS.

HSPGs act as potential receptors for lipoprotein remnants or facilitate the uptake by ligand transfer to LRP. The HSPGLRP pathway mediates the internalization either by transfer of the remnants from HSPGs to LRP or by binding of the lipoprotein remnants to HSPGs complexed with LRP. ${ }^{1)}$ HSPGs alone can function as a receptor and mediate the uptake of lipoprotein remnants. ${ }^{21)}$

Heparinase releases the sulfated GAG side chains from HSPGs and inhibits the plasma clearance and liver uptake of remnant lipoproteins. ${ }^{222}$ The treatment of a variety of cells with heparinase significantly inhibited the binding and uptake of apoE-enriched remnant lipoproteins. ${ }^{223)}$ Heparin impedes the binding of apoE-containing lipoproteins with HSPGs. ${ }^{221)}$ Lactoferrin, an iron-binding glycoprotein, impairs the clearances of CM and VLDL and decrease the liver uptake by inhibiting and blocking interaction of apoE with LRP and HSPGs. ${ }^{24,225)}$ This inhibitory effect of lactoferrin is attributed to an arginine/lysine-rich sequence at position 25-31 that resembles the receptor-binding region of apoE. ${ }^{226}$ )

\section{LIPID COMPONENTS}

6.1. SM SM is one of the major lipids in lipoproteins. The liver synthesizes sphingolipids de novo and incorporates the newly synthesized SM into VLDL. ${ }^{227)}$ The ratio of SM/ PC widely varies among lipoprotein subclasses and lipoprotein SM concentration is affected by several factors. ${ }^{228-234)}$ The $\mathrm{SM} / \mathrm{PC}$ ratio in VLDL is 0.25 . Unlike $\mathrm{PC}, \mathrm{SM}$ is not degraded by LPL, HL, or LCAT, and the transfer of SM among lipoproteins as well as between lipoproteins and cell membranes is slower than that of other PL. ${ }^{235-237)}$ SM removal from plasma is absolutely dependent on hepatic clearance. Thus, SM becomes enriched in VLDL remnants, and the SM/PC ratio in LDL is quite high $(0.5) .{ }^{238)}$ In hypercholesterolemic patients, the $\mathrm{SM} / \mathrm{PC}$ molar ratio in LDL was increased to $0.522 .{ }^{229}$ ) Lipoprotein SM concentration is raised by lipopolysaccharide, dietary cholesterol, casein, and olive oil, and the SM/PC ratio was higher in all lipoproteins in apoE knockout mice compared with wild-type mice. ${ }^{230,231,233,234,239)}$ Plasma SM levels show a significant, although moderate, correlation with remnant cholesterol levels; however, in multivariate analysis, plasma SM level remains as a significant predictor of CHD even after additional adjustment for remnant lipoprotein cholesterol levels. ${ }^{240)}$ LDL extracted from human atherosclerotic lesions is highly enriched in SM compared with plasma LDL. ${ }^{238)}$

The hydrophobic region of natural SM consists of highly saturated acyl chains and thus SM has more ordered acyl chain structures than PC. ${ }^{199)}$ Both the amino and hydroxyl groups of sphingosine participate in intramolecular and intermolecular hydrogen bonding, which are not found in PC. The hydrogen bonding capacity of SM in the backbone region, in addition to a condensed acyl chain organization, results in increased packing and hence decreased hydration of the head group region. ${ }^{199)}$ I have revealed that the incorporation of SM 
into lipid emulsions markedly increases acyl chain order and decreases head group hydration of the surface monolayers ${ }^{199)}$ (Fig. 1B). Therefore, SM is a structural and functional determinant at the lipoprotein surface.

The presence of SM delays the removal of emulsion particles from animal plasma. ${ }^{241-243)} \mathrm{SM}$ strongly inhibits the LPLmediated lipolysis in the emulsion particles. ${ }^{198,199,243)}$ Kinetic studies of the lipolysis rates have shown that the incorporation of SM into the emulsion surface causes an increase in $K_{\mathrm{m}}{ }^{\text {app }}$ and a decrease in $V_{\max }^{\text {app }}$, indicating that $\mathrm{SM}$ inhibits the lipolysis by decreasing both affinity for substrates and catalytic activity of LPL. ${ }^{198,199)}$ The lipid binding of LPL is presumed to depend on the structure of the head group region, which is affected by the presence of SM. ${ }^{199)}$ It has been suggested that the strong condensation in the head group region caused by SM inhibits LPL binding to the lipid surface and thus decreases the LPL activity. ${ }^{199)}$

To clarify the role of SM in lipoprotein uptake, I have prepared lipid emulsions containing triolein (TO), PC and SM as model particles of lipoproteins. ApoE binding studies have revealed that the incorporation of SM into the emulsion surface reduces the binding capacity of apoE without changing the affinity. ${ }^{244)}$ The increased surface packing in SM-containing emulsions may therefore result in the decrease in the insertion of apoE into the surface layer. SM in the emulsion surfaces reduces the apoE-mediated uptake of the particles by HepG2 human hepatoma cells, which is consistent with the decreased binding amount of apoE to the SM-containing emulsion surfaces. ${ }^{244}$ The receptor-active state of apoE may be unfavorable for the SM-containing particles because of the increased packing stress. The addition of lactoferrin almost abolishes the effect of apoE on the emulsion uptake, indicating that lactoferrin-sensitive pathways contribute to the apoE-mediated uptake of the emulsion particles. ${ }^{244)}$ The treatment of the cells with heparinase results in decreased uptake of the emulsion particles in the presence of apoE. ${ }^{244)}$ Therefore, HSPGs and LRP are mainly involved in the apoE-mediated uptake of lipid emulsions by HepG2 cells. ${ }^{244,245)}$ The apoE-mediated uptake of the lipid emulsions is inhibited by the presence of apoC-II or apoC-III. ${ }^{244,245)} \mathrm{SM}$ in the emulsion surface enhances the inhibitory effects of apoC-II and apoC-III on the apoE-mediated uptake of emulsion particles. ${ }^{244)}$ The incorporation of SM into the emulsion surface reduces the amount of apoE binding in human plasma and increases the ratios of apoC-II and apoCIII to apoE. ${ }^{243)}$ More displacement of apoE by apoC-II or apoC-III from SM-containing particles may result in greater reduction of cell uptake.

Strikingly, LPL promotes the uptake of emulsion particles into HepG2 cells. ${ }^{244)}$ However, the effect of LPL on the emulsion uptake is decreased by replacing surface PC with SM. ${ }^{244)}$ It is conceivable that the mechanism for the inhibition of LPL-mediated uptake is the impaired binding of LPL to the SM-containing particles. In the presence of LPL, lactoferrin almost prevents the emulsion uptake, indicating that HSPGs and LRP are the major contributors to the LPL-mediated uptake of lipid emulsions by HepG2 cells. ${ }^{244)}$ Taken together, these findings suggest that the SM-induced changes in the binding properties of apolipoproteins and LPL are associated with decreased hepatic uptake of lipoproteins.

6.2. FC The amount of $\mathrm{FC}$ in lipoproteins regulates their metabolism. FC is a major surface lipid of CM remnants.
When CM is converted to chylomicron remnant by the action of LPL, the relative content of FC increases in the remnant. ${ }^{246}$ ) The FC/PL ratio of the remnants in human serum in the postprandial state is close to $1 .{ }^{228)}$ The FC/PL ratios in VLDL and LDL are 0.78 and 0.73 , respectively. ${ }^{247}$ )

FC can distribute between the surface and core phases in lipid emulsions and lipoproteins. From the surface-core phase equilibrium, over $80 \%$ of $\mathrm{FC}$ is accommodated in the surface phase in emulsions consisting of TG and PC. ${ }^{248)} \mathrm{FC}$ induces a motional restriction of $\mathrm{PC}$ and a rigidification of the emulsion surface with increasing content. ${ }^{248)} \mathrm{FC}$ is associated with surface $\mathrm{PC}$ but located deep in the inner hydrocarbon region. ${ }^{248)} \mathrm{I}$ have demonstrated that FC increases the acyl chain order and head group hydration of the surface PC layer of emulsions ${ }^{249}$ ) (Fig. 1B). The acyl chain region of FC-containing emulsion surface layer is more rigid than that of emulsion surface without FC. Moreover, FC enrichment on the emulsion surface leads to the separation and hydration of PC head groups.

The amount of FC in emulsion particles regulates the metabolism by affecting the binding of apolipoproteins to the particle surface. Emulsions with a high content of FC bind less apoA-1, apoA-IV and apoCs, and the relative amount of apoE is increased. ${ }^{250}$ The presence of FC facilitated the removal of emulsion particles from plasma. ${ }^{243)}$ Interestingly, FC does not affect the lipolysis rates although both TG solubility in PC monolayer and apoC-II binding are decreased, indicating that neither TG solubility nor amount of apoC-II binding are determinants of LPL-mediated lipolysis. ${ }^{198)}$

I have used lipid emulsions containing TO, PC and FC as a model for TG-rich lipoprotein remnants. ${ }^{245,249,251)}$ Emulsions rich in FC are metabolized like CM remnants. ${ }^{250)}$ FC markedly increases the apoE-binding maximum of emulsions without changing the binding affinity. ${ }^{249}$ ) The binding maximum of apoE is correlated with the hydration between PL polar head groups at the emulsion surface, indicating that the PL head group separation plays a crucial role in apoE binding. ${ }^{249}$ At the emulsion surface, the inverse wedge-shaped lipid, FC, releases the stress and increases the number of binding sites for apoE. Although both SM and FC at the emulsion surface increase the acyl chain packing, the apoE-binding maximum is lowered by SM but elevated by FC. ${ }^{249)}$ Thus, an enhancement in the apoE-binding maximum of FC-containing emulsions may be caused by an increase in PC head group separation but not by an increase in acyl chain packing.

FC in the emulsion surface increases the amount of apoE bound to the particles, but had no effect on the binding amount of apoC-III, suggesting that the binding of apoC-III is insensitive to the degree of PC head group separation at the emulsion surface. ${ }^{245)}$ ApoC-III reduces the binding of apoE to the emulsion particles. ${ }^{245}$ ) The binding amount of apoE correlates inversely with the binding amount of apoC-III to the lipid emulsions. ${ }^{245)}$ Surface FC alleviates the inhibitory effect of apoC-III on apoE binding to the emulsion surface, and increases the total binding of apoE and apoC-III. ${ }^{245}$ ) $\mathrm{FC}$ at the emulsion surface may increase the number of the apoE binding sites rather than the apoC-III binding sites.

FC in the emulsion surface enhances the apoE-mediated uptake by $\mathrm{J} 774$ mouse macrophages by increasing the amount of apoE bound to the emulsion particles. ${ }^{249)}$ Lactoferrin or heparin treatment dramatically prevents the apoE-mediated uptake of the emulsions into J774 macrophages, suggesting 
that HSPGs and LRP are predominantly involved in the apoEmediated uptake. ${ }^{249)}$ In the presence of apoE, the uptake of FC-containing emulsions by HepG2 cells is higher than that of emulsions without FC. ${ }^{245}$ ) The apoE-mediated uptake of the emulsion particles decreases with apoC-III concentration. ${ }^{245)}$ Despite a sufficient amount of apoE bound to FC-containing emulsions, apoC-III almost abolished the cellular uptake of the emulsions via HSPG and LRP pathways. ${ }^{245}$ Excluding the case of FC-containing emulsions in the presence of both apoE and apoC-III, the emulsion uptake is positively correlated with the amount of apoE bound to emulsions. ${ }^{245}$ ) In the presence of apoE, there are inverse correlations between the emulsion uptake and the binding of apoC-III. ${ }^{245)}$ Thus, apoC-III bound to emulsion particles may prevent the apoE-mediated uptake. It is possible that at the FC-containing surface, apoC-III leads to the receptor-inactive conformation of the apoE-N-terminal domain or masks the cluster of positively charged amino acids of apoE involved in the binding to LRP and HSPG, in addition to the attenuation of apoE binding to the particle surface. These observations suggest that apoC-III impedes the binding and activation of apoE at the lipoprotein surface. Furthermore, FC at the surface of lipoprotein remnants may modulate these functions of apoC-III.

6.3. CE CE, along with $\mathrm{TG}$, is the major core component of plasma lipoproteins. During the transport of plasma TG-rich lipoproteins, the CE content of these lipoproteins is progressively increased by the action of CETP. The increase of CE replaces the loss of TG in the hydrophobic core of these particles. The core replacement of TG with cholesteryl oleate (CO) has little effect on the surface rigidity, despite the large difference in the core mobility. ${ }^{248)}$ However, in the presence of $\mathrm{FC}$, the core replacement with $\mathrm{CO}$ results in a marked increase in the surface rigidity. ${ }^{248}$ Although FC preferentially partitions into the surface, the incorporation of $\mathrm{CO}$ into core TO increases the distribution of FC into the core phase, arising from the association of FC with $\mathrm{CO}$ in the core. Over $80 \%$ of the FC is associated with the surface phase in emulsions consisting of TG and $\mathrm{PC}$, whereas only about one-half of the $\mathrm{FC}$ is located at the surface in emulsions consisting of $\mathrm{CO}$ and PC. ${ }^{248)}$ The core replacement with CO modulates the surface properties of the emulsion particles through the redistribution of FC in the surface layers.

The increased amount of $\mathrm{CO}$ in the emulsion core retards the emulsion clearance from rat plasma. ${ }^{252}$ Replacing core TO with CO markedly decreases the apoE binding capacity to emulsion particles without changing the binding affinity. ${ }^{252)}$ The uptake of TO-PC emulsions into HepG2 cells is greatly increased by the addition of apoE, but the effect of apoE decreased with increasing $\mathrm{CO}$ content. ${ }^{252)}$ The physical state of core lipids is modulated by the content of $\mathrm{CE}$ and plays a crucial role in lipoprotein metabolism.

6.4. Particle Size Apo-B100 binds to LDLR only after the conversion of large VLDL to smaller LDL. ${ }^{104)}$ The removal of the C-terminus of apo-B100 on VLDL dramatically enhances the apoB-mediated receptor-binding activity. ${ }^{108)}$ It has been proposed that, during the lipolysis of VLDL to LDL, the C-terminus of apoB-100 changes its conformation to allow interaction with LDLR. ${ }^{108)}$ The conformational changes in apoB-100 are limited to particular regions in the metabolic cascade from VLDL to LDL. ${ }^{253)}$

ApoE displays no binding preference between small and large emulsion particles. ${ }^{254)}$ However, apoE enhances the uptake of both VLDL-size and remnant-size emulsion particles by J774 macrophages, but the effect is greater on the uptake of larger particles compared to the uptake of smaller particles. ${ }^{255)}$ Addition of apoC-III almost completely displaces apoE from small VLDL particles, while larger VLDL contain tightly bound apoE, which are not displaced by apoC-III. ${ }^{256)}$ The ratio of apoCs/apoE on the emulsion particles in serum is inversely correlated with particle size, and the particle size shows a positive correlation with the association of the emulsions with the liver. ${ }^{257)}$

ApoCs are mainly associated with HDL in the fasting state, whereas in the fed state, they preferentially redistribute to the surfaces of CM and VLDL particles. ${ }^{46)} \mathrm{CM}$-size lipid particles do not take up free apoA-I and apoA-IV but rather apoCs in the presence of HDL. ${ }^{258)}$ ApoC-II and apoC-III bound to the large emulsions as strongly as to the small emulsions. ${ }^{190)}$ ApoC-II and apoC-III may prefer less positively curved surfaces (i.e., large lipid particles) due to the convex hydrophobic face of apoC-II and the relatively large hydrophobic surface of amphipathic helices of apoC-III. ${ }^{259)}$

HL hydrolyzes lipoprotein-TG, but has a higher affinity for the smaller and denser LDL and HDL particles. ${ }^{35)}$ HL works more effectively on the smaller, denser VLDL particles and least efficiently on $\mathrm{CM}^{260}{ }^{26}$

The action of LPL is greater on CM than on VLDL. ${ }^{28)}$ The susceptibility of large VLDL particles to hydrolysis by LPL is greater than that of the smaller VLDL. ${ }^{261)}$ The preference of LPL for different lipoproteins seems to be directly related to the size of the particles. The weight fraction of TO in the emulsion surface monolayer of PC is independent of the relative concentration of TO in the particle or of the size of the particle. ${ }^{262)}$ Kinetic parameters of the LPL-mediated lipolysis activated by apoC-II indicate that LPL has similar apparent maximal activities in large and small emulsions. Binding parameters, dissociation constant and binding maximum, of apoC-II for large and small emulsions are similar. ${ }^{190)} \mathrm{ApoE}$ efficiently inhibited the LPL-mediated lipolysis of TG-rich emulsions in vivo and in vitro. ${ }^{142}$ Competition binding assays of different lipoproteins demonstrated that the binding affinity of CM to LPL was almost 50-fold higher than VLDL, and smaller hydrolyzed CM had less affinity than the larger $\mathrm{CM}$, indicating a linear relation between $\mathrm{CM}$ size and binding affinity to LPL. ${ }^{263)}$ In the kinetic model for heterogeneous enzyme catalysis that includes LPL-apoC-II interactions, $K_{\mathrm{m}}{ }^{\text {app }}$ is affected by the binding affinity of LPL to the lipid interface. ${ }^{189)}$ Plasma apolipoproteins other than apoC-II are responsible for the regulation and inhibition of LPL action in a particle size-dependent manner.

I have prepared large (ca. $120 \mathrm{~nm})$ and small $(c a .35 \mathrm{~nm})$ emulsions consisting of TO and PC as the models of CM and remnants, respectively. Both large and small emulsions are hydrolyzed at similar rates in the presence of apoC-II. ${ }^{264)}$ ApoCIII and apoE work as LPL-inhibitors of the lipolysis activated by apoC-II. ${ }^{264)}$ The addition of apoC-III reduces the lipolytic velocities in both large and small emulsions. ${ }^{264)}$ The inhibition by apoE in small emulsions is more effective than for large emulsions. ${ }^{264)}$ ApoA-I inhibits the LPL-mediated lipolysis of small emulsions more effectively. ${ }^{264)}$ ApoA-I and apoE decrease both $V_{\max }$ app and $K_{\mathrm{m}}$ app as uncompetitive inhibitors, probably retarding the LPL-apoC-II-TO complex formation at 
the emulsion surface monolayer. ${ }^{264)}$ On the other hand, apoCIII decreases $V_{\max }^{\text {app }}$ for both large and small emulsions and slightly increased $K_{\mathrm{m}}$ app only for large emulsions, suggesting that apoC-III influences the lipolysis by inhibiting both formation of the enzyme-substrate complex and binding of LPL to emulsions. ${ }^{264)}$ ApoA-I in plasma may work as an intense inhibitory factor in the LPL reaction, especially for small particles. Normal human plasma contains sufficient amounts of apoA-I to inhibit the lipolytic activity of LPL. In human serum, the binding behaviors of apolipoproteins are very different between small and large emulsion particles. ${ }^{264)}$ The densities of apoC-II, apoC-III and apoE bound to large emulsion surfaces are greater than the respective values to small ones, while apoA-I more preferentially binds to small emulsion surfaces than large ones. ${ }^{264)}$ ApoA-I displaces apoC-II, apoC-III and apoE from small particle surfaces and plays a major role in regulating other apolipoprotein binding to the particles. The dissociation constant of apoA-I for the large emulsion particles is much greater than that for the small emulsion particles. ${ }^{190)}$ The apoA-I binding capacities of lipid emulsions is correlated with the difference in the packing of surface layer ${ }^{190)}$ and well explained in terms of the space available for accommodation of tandem repetitive class A amphipathic helical domains among PC head groups at the lipid particle surface. ${ }^{265)}$ In response to various lipid surfaces, apoA-I may be induced to undergo a conformational switch leading to a gross structural alteration of the protein. ${ }^{124)}$ ApoA-I in plasma may regulate the lipolysis of TG-rich lipoproteins in a size-dependent manner, in addition to the well known inhibitory effects of apoC-III and apoE.

\section{LIPOPROTEIN MODIFICATION}

7.1. CM Remnants Postprandial hyperlipidemia is an independent risk factor for atherosclerosis. ${ }^{7)}$ There is a significant correlation between plasma apoB-48 levels and severity of coronary atherosclerosis. ${ }^{266)} \mathrm{CM}$ undergoes the hydrolysis of TG by LPL in the capillary beds of peripheral tissue, and, as a result, $\mathrm{CM}$ remnants are produced. ${ }^{34)} \mathrm{CM}$ remnants generated in proximity to the artery wall during the postprandial period are atherogenic. The FC/TG ratio is increased by $17-$ fold in $\mathrm{CM}$ remnants compared with $\mathrm{CM}^{267)} \mathrm{CM}$ remnants are characterized by high FC content at the surface, which is different from LDL containing high amounts of $\mathrm{CE}$ in the core. CM remnants contain approximately 40-fold more FC per particle than LDL. ${ }^{268)} \mathrm{CM}$ is too large to infiltrate into the vessel wall across the endothelial layer, but the diameter of $\mathrm{CM}$ remnants is small enough to penetrate the endothelium. ${ }^{47)}$ $\mathrm{CM}$ remnants are rich in apoE, which plays a crucial role in lipoprotein metabolism. The major route of CM remnant uptake into macrophages occurs via LRP, while LDLR and scavenger receptors play minor roles. ${ }^{73)}$ HSPGs participate in the remnant uptake by associating with LRP or acting alone as receptors. ${ }^{269)}$ Similar to scavenger receptors, HSPGs and LRP are not suppressed by intracellular cholesterol content. ${ }^{270)}$ CM remnants induce the accumulation of both TG and cholesterol in macrophages, and the rate of remnant uptake is influenced by the type of dietary fat in the particles. ${ }^{73}$ In striking contrast to LDL, the oxidation of CM remnants suppresses the induction of foam cell formation. ${ }^{73)} \mathrm{CM}$ remnants are cytotoxic to macrophages and smooth muscle cells. ${ }^{271)}$ The
CM remnant-like particles downregulate the pro-inflammatory chemokine and cytokine secretion by monocytes and macrophages. ${ }^{272,273)}$

To investigate the mechanisms of $\mathrm{CM}$ remnant-induced atherosclerosis, I have prepared FC-containing emulsion particles as a model for CM remnants. ApoE promotes the uptake of lipid emulsions by $\mathrm{J} 774$ macrophages. ${ }^{249)}$ The HSPGLRP pathway plays an important role in the apoE-mediated emulsion uptake by $\mathrm{J} 774$ macrophages. ${ }^{249}$ ) The uptake of FC-containing emulsions, but not LDL or acetylated LDL (acLDL), induced cytotoxicity to J774 macrophages. ${ }^{249,251)}$ The cytotoxicity induced by FC-containing emulsions is attenuated in the presence of heparin, indicating that the HSPG-LRPmediated endocytosis of FC-rich particles induces a cytotoxic response. ${ }^{251)}$ FC-containing emulsions increase the FC content of J774 macrophages. ${ }^{251)}$ However, the cells incubated with FC-containing emulsions contain only a low level of CE. ${ }^{251)}$ Unlike LDL, acLDL particles remarkably increase the CE content of the cells. ${ }^{251)}$ AcLDL particles also increase the cellular FC to the level of FC-containing emulsion-loaded cells, but do not trigger cell death, indicating that the cytotoxicity is not correlated with the absolute levels of cellular FC. ${ }^{251)} \mathrm{Ca}$ thepsin- $\mathrm{L}$ is the most active lysosomal protease in the degradation of intracellular or endocytosed protein substrates. ${ }^{274,275)}$ FC-containing emulsions induce the leakage of cathepsin-L to cytosol, which is not observed for acLDL. ${ }^{251)}$ Upon lysosomal destabilization, cathepsins are released from lysosomes to cytosol. ${ }^{276-278)}$ Inhibition of the activity of cathepsin-L recovers the viability of macrophages that ingested FC-containing emulsions. ${ }^{251)}$ These findings indicate that the treatment of FC-containing emulsions causes the lack of lysosomal stability. Cathepsins are known to promote cleavage of Bid, an apoptotic member of the Bcl-2 family, resulting in the release of cytochrome $c$, an initiating agent for apoptosis in mitochondria. ${ }^{279,280)}$ Cathepsins are implicated in atherosclerosis-based vascular disease. ${ }^{63)}$ The expression of lysosomal cathepsin-L is increased in atherosclerotic plaques and correlated with apoptosis. ${ }^{281)}$ FC-containing emulsions induce the activation of caspase-3. ${ }^{251)}$ These findings indicate that FC-containing emulsion-induced apoptosis at least partially originates from the leakage of cathepsin-L. Considering that FC alters the physical properties of biological membranes, the uptake of FC-containing emulsions may cause FC enrichment in lysosomal membranes, resulting in their destabilization. $\mathrm{CE}$ is scarcely detected after the internalization of FC-containing emulsions, suggesting that FC from emulsion particles is not esterified by ACAT in the ER, due to the impairment of the FC transport from lysosomes to the ER mediated by NPC1 and NPC2. It is possible that NPC1 and NPC2 cannot efficiently transport the $\mathrm{FC}$ molecules rapidly accumulated in lysosomes without hydrolysis by lysosomal acid lipase, and that the direct incorporation of FC molecules into the lysosomal membranes and/or cholesterol crystallization cause lysosomal disruption and apoptosis.

7.2. SMase SMase hydrolyzes SM to phosphorylcholine and ceramide, a lipid second messenger in apoptosis, cell differentiation, and cell proliferation. ${ }^{282}$ A variety of cell types present in atherosclerotic lesions secrete SMase. ${ }^{283)}$ Arterial wall SMase is involved in atherogenesis. SMase secretion by endothelial cells is stimulated by inflammatory cytokines, such as interleukin- $\beta$ and interferon- $\gamma^{283)}$ LDL extracted 
from human atherosclerotic lesions is highly enriched in SM compared with plasma LDL. ${ }^{230}$ ) The ceramide content of aggregated LDL in atherosclerotic lesions is 10 - to 50 -fold higher than that of plasma LDL. ${ }^{284}$ LDL isolated from human plasma possesses SMase activity. ${ }^{285)}$ In LDL aggregates, the SMase of LDL may catalyze the formation of ceramide in the contacting, adjacent lipoproteins. ${ }^{50}$ These LDL aggregates potently induce macrophage foam cell formation. ${ }^{74,286)}$ The formation of ceramide from SM represents a critical step in atherosclerosis.

In emulsion particles, SMase hydrolyzes SM molecules, and yields ceramide molecules, which are retained in the particles, and water-soluble phosphorylcholine molecules, which are released. ${ }^{60)}$ Although PC can act only as acceptors of hydrogen bonds, SM and ceramide can act as both acceptors and donors through their hydroxyl and amide group. Treatment of LDL particles with SMase induces both aggregation and fusion of the particles, which depend on the accumulation of ceramide within the particles. ${ }^{61,74,284)}$ I have shown that SMase promotes the aggregation and fusion of lipid emulsions depending on ceramide formation. ${ }^{287,288)}$ I have also confirmed the existence of ceramide-enriched domains in emulsion particles by confocal fluorescence microscopy ${ }^{288}$ ) (Fig. 4). Two fluorescent lipid analogs distinguish the fluid and ordered membrane phases. DiI- $\mathrm{C}_{18}$ predominantly partitions into the ordered membrane phases, whereas BODIPY-PC having a bulky moiety on an acyl chain favors the fluid phase. ${ }^{289-291)}$ The confocal images of ceramide-containing emulsions with two fluorescent probes have demonstrated the three-dimensional microdomains enriched in ceramide. ${ }^{288)}$ These ceramide-enriched domains present a variety of morphologies. In contrast, SM at the emulsion surface has no influence on the phase behavior. ${ }^{288)}$ SMase also induces the formation of ceramide-enriched domains extending from emulsion core to surface. ${ }^{288)}$ The SM-containing emulsion particles become larger after SMase treatment, demonstrating SMase leads to the fusion as well as the aggregation of emulsion particles. ${ }^{288)}$ Microdomain formation arises due to the properties of ceramide headgroup, and the large hydration of the phosphorylcholine group in SM may cause strong steric hindrance prohibiting hydrogen bonding in SM-SM interactions. ${ }^{292)}$ Ceramide molecules are likely to cluster and form three-dimensional, but not in-plane, microdomains in lipoprotein particles as well as emulsions. The ceramide-enriched domains may act as non-polar spots at the particle surface and lead initially to particle aggregation through hydrophobic associations between the domains in different particles. ${ }^{61,282)}$ Thus, a driving force for particle aggregation is the formation of ceramide-enriched domains. ApoE bound on the emulsion surface prevents the SMase-induced aggregation and fusion of the particles, but does not affect the SMase enzymatic activity. ${ }^{288)}$ Ceramide increases the amount of apoE bound to emulsion particles. ${ }^{288)} \mathrm{I}$ have proposed apoE prefers to bind on ceramide-enriched domains exposed on particle surface, and thus inhibits the hydrophobic interaction between the particles followed by aggregation or fusion. ${ }^{288)}$

SMase modification of LDL facilitates their uptake by macrophages and foam cell formation. ${ }^{74,286)}$ In the presence of SMase, the endocytosis of LDL is enhanced and leads to an increase in LDL degradation and CE accumulation in J774 and mouse peritoneal macrophages. ${ }^{74)}$ SMase-treated LDL is degraded at higher rates than native LDL in a variety of cell lines. ${ }^{293)}$ LDL association with smooth muscle cells in the presence of SMase is greater than in the absence of SMase. ${ }^{294)}$ The uptake and degradation of lipoproteins from apoE-knockout mice by macrophages are dramatically increased by SMase, but neither LDLR nor scavenger receptors, CD36 or class A scavenger receptor, are involved in the process. ${ }^{286)}$ However, J774 macrophages internalize and degrade both matrix-retained and non-retained SMase-aggregated LDL, which are mediated partially by LRP. ${ }^{81)}$ The size of SMase-aggregated LDL $(c a .100 \mathrm{~nm})$ is too small to elicit a phagocytic response. ${ }^{74,295)}$ SMase-treated aggregated and fused LDL bound to human aortic PGs more tightly in the affinity column than native LDL. ${ }^{54,61)}$ Furthermore, large amounts of ceramide ingested together with lipoproteins by macrophages possibly induce apoptosis. Therefore, elevation in plasma SM levels may result in the accumulation of ceramide in the arterial intima, leading to the development of atherosclerosis.

I have demonstrated that the generation of ceramide by SMase in emulsion particles increases their ability to be taken up by J774 macrophages without apolipoproteins. ${ }^{287)}$ The emulsion uptake is negatively correlated with the degree of particle aggregation by SMase. ${ }^{287)}$ The uptake of large SMcontaining emulsions $(\mathrm{ca} .230 \mathrm{~nm})$ is much lower than that of normal-sized SM-containing emulsions (ca. 120 nm), indicating the uptake of the emulsion particles is largely dependent on their size. ${ }^{287)}$ The uptake of ceramide-containing emulsions is significantly larger than that of SM-containing emulsions. ${ }^{287}$ Ceramide formed in the particles by SMase enhances their uptake into $\mathrm{J} 774$ macrophages, although the increase in size or particle aggregation decreases their uptake. HSPGs and LRP are crucial for the ceramide-enhanced emulsion uptake, because heparin or lactoferrin inhibit the emulsion uptake. ${ }^{287)}$ LRP is largely confined to clathrin-coated pits, which measure $180-240 \mathrm{~nm}$ in diameter. ${ }^{296,297)}$ It is likely that large particles are restricted to enter clathrin-coated pits, and thus the interaction of large particles with LRP is impaired. ApoE further increases the uptake of ceramide-containing emulsions compared with SM-containing emulsions, by increasing binding of apoE to ceramide-containing particles. ${ }^{287,288)}$ ApoE enhances the HSPG and LRP-mediated uptake of particles modified by SMase, not only due to the increased binding of apoE to ceramide-containing lipoproteins but also to the inhibition of particle aggregation. In the presence of LPL, ceramidecontaining emulsions exhibit significantly higher uptake than SM-containing emulsions. ${ }^{287)}$ However, unlike apoE, LPL similarly enhances both SM-containing and ceramide-containing emulsion uptake. ${ }^{287)}$ From these findings, the generation of ceramide in lipoproteins by SMase may facilitate the macrophage uptake via HSPG and LRP pathways and play a crucial role in foam cell formation. Thus, ceramide may act as an important atherogenic molecule.

7.3. ApoB Denaturation In early atherosclerotic lesions, even before atheroma appears, symptomatic patients have significantly more arterial apoB deposits than patients without cardiovascular events. The modification of LDL leads to a conformational change in apoB. It has been proposed that the misfolding of apoB, its aggregation, resistance to proteolysis, and cytotoxicity are common motifs shared by modified LDL and amyloidogenic proteins. ${ }^{298)}$ The misfolded apoB that accumulated and aggregated in atherosclerotic lesions may induce cytotoxic effects. ${ }^{298)}$ The secondary structure and 
conformation of apoB in LDL are imposed by lipid-protein interactions and dynamics. ${ }^{298)}$ Following an alteration in the water-lipid interface as a result of oxidation of lipids, the structure becomes destabilized and misfolded. ${ }^{298)}$ The secondary structure and conformation of apoB are severely altered in electronegative LDL (LDL(-)), a fraction of oxLDL isolated in vivo. ${ }^{299)}$ Decreased $\mathrm{CD}$ signal of apoB and shorter tryptophan fluorescence lifetime are observed for oxLDL, indicating that the secondary structure is changed, and that apoB unfolds into a conformation in which tryptophan residues are more exposed to water following oxidation. ${ }^{300}$ The oxidation of LDL generates characteristic amyloid-like structures that are recognized by macrophages. ${ }^{301)}$ The $\operatorname{LDL}(-)$ subfraction has strong immunoreactivity with an amyloid oligomer-specific antibody. ${ }^{302)}$ ApoB-100 in LDL( $(-)$ is misfolded, and this modification primes the aggregation of native LDL, similar to the protein amyloidogenesis. ${ }^{303)}$ During aggregation, a dominostyle spread of apoB-100 misfolding from LDL(-) to all of the LDL particles occurs. ${ }^{303)}$ It has been predicted that a structure in the $\alpha_{2}$ domain is highly prone to a conformational switch from a native $\alpha$-helical arrangement toward cross- $\beta$ aggregation with other protein molecules. ${ }^{303)}$ It is conceivable that apoB is dissociated partially or entirely from the LDL particle and is folded incorrectly as a result of several modifications in arterial walls, which may contribute to the development of atherosclerosis.

By small angle neutron scattering in combination with advanced shape reconstitution algorithms, a low resolution model of apoB has shown that the lipid-free protein adopts an expanded curved shape composed of distinct domains connected to flexible regions. ${ }^{304}$ Sodium deoxycholate (NaDC) is a reasonable detergent to solubilize lipid-free apoB. ${ }^{305)} \mathrm{ApoB}$ in $\mathrm{NaDC}$ has a mean length of $65 \mathrm{~nm}$ and appears to be long, thin, apparently flexible molecules. ${ }^{306)}$ I have shown that the $\mathrm{CD}$ spectrum of lipid-free apoB in $\mathrm{NaDC}$ is slightly different from that of apoB bound to LDL (LDL-apoB). ${ }^{307)}$ The analysis of the $\mathrm{CD}$ signal has revealed that the secondary structure of LDL-apoB is characterized by a large content of $\alpha$-helix and smaller amount of $\beta$-sheet, $\beta$-turn and random coil. ${ }^{99,307)}$ The $\alpha$-helix content of lipid-free apoB is lower than that of LDLapoB, while the content of random coil is higher. ${ }^{307)}$ However, the overall secondary structure of lipid-free apoB is highly conserved, suggesting the solubilization of lipid-free apoB by NaDC may lead to only partial unfolding of the secondary structure in apoB rather than global protein unfolding as shown in oxLDL or LDL $(-){ }^{299,300,303,307,308)}$

I have investigated the cytotoxic effect of lipid-free apoB solubilized with $\mathrm{NaDC}$, as a model for denatured apoB. Lipidfree apoB has cytotoxicity to J774 macrophages, HepG2 cells and Chinese hamster ovary cells, whereas LDL-apoB and lipid-free apoA-I have no effect on the cell viability. ${ }^{307)}$ Lipidfree apoB induces apoptosis in $\mathrm{J} 774$ macrophages assessed by caspase- 3 activation and annexin $\mathrm{V}$ binding. ${ }^{307)}$ The uptake of lipid-free apoB by $\mathrm{J} 774$ macrophages is greater than that of LDL-apoB, indicating the uptake of apoB is promoted by the dissociation of apoB from LDL particles. ${ }^{307)}$ LDLR, HSPGs, and class A scavenger receptor are involved in the uptake of lipid-free apoB, but the uptake of lipid-free apoB is not involved in the cytotoxicity. ${ }^{307)}$ Lipid-free apoB, but not LDLapoB or apoA-I, disrupts the lipid bilayer of large unilamellar vesicles containing calcein. ${ }^{307)}$ A lipid-free apoB induces an increase in the intracellular $\mathrm{Ca}^{2+}$ concentration, which is brought about by influx of extracellular $\mathrm{Ca}^{2+}$ but not by calcium mobilization from intracellular $\mathrm{Ca}^{2+}$ stores. ${ }^{307)}$ Furthermore, the inhibitors for the uptake of lipid-free apoB do not show any inhibitory effects on the membrane disruption. ${ }^{307)}$ Taken together, lipid-free apoB is considered to induce cell death by disturbance of the plasma membrane. The high affinity of apoB for lipids may promote the binding of lipid-free apoB to the plasma membrane of the cells. Denatured apoB accumulated in atherosclerotic lesions may lead to cell death. In addition to other lipid components in modified LDL, apoB itself has an ability to induce apoptosis and plays a crucial role in the development of atherosclerotic lesions.

\section{FUTURE DIRECTIONS}

This review summarizes the current understanding of the metabolism of apoB-containing lipoproteins and the initiation of atherosclerosis. Numerous studies have revealed the properties of apolipoproteins and lipoprotein receptors, and have explored the mechanism of atherogenesis. Nevertheless, the detailed molecular mechanisms are not clearly understood. The interactions between different apolipoproteins on lipoprotein particles are largely unknown. In particular, the structure and functions of apoB are still only partly elucidated. Moreover, intracellular lipid transport and metabolism are extremely complex processes. A thorough understanding of the mechanisms involved in lipoprotein metabolism and atherogenesis will lead to the development of novel therapeutic strategies.

Conflict of Interest The author declares no conflict of interest.

\section{REFERENCES}

1) Mahley RW, Ji ZS. Remnant lipoprotein metabolism: key pathways involving cell-surface heparan sulfate proteoglycans and apolipoprotein E. J. Lipid Res., 40, 1-16 (1999).

2) Segrest JP, Jones MK, De Loof H, Dashti N. Structure of apolipoprotein B-100 in low density lipoproteins. J. Lipid Res., 42, 1346-1367 (2001).

3) Lund-Katz S, Liu L, Thuahnai ST, Phillips MC. High density lipoprotein structure. Front. Biosci., 8, d1044-d1054 (2003).

4) Sacks FM. The relative role of low-density lipoprotein cholesterol and high-density lipoprotein cholesterol in coronary artery disease: evidence from large-scale statin and fibrate trials. Am. J. Cardiol. 88 (12A), 14N-18N (2001).

5) Duttaroy AK. Therapy and clinical trials. Curr. Opin. Lipidol., 13, 585-587 (2002)

6) Stampfer MJ, Krauss RM, Ma J, Blanche PJ, Holl LG, Sacks FM, Hennekens CH. A prospective study of triglyceride level, low-density lipoprotein particle diameter, and risk of myocardial infarction. JAMA, 276, 882-888 (1996).

7) Goldberg IJ, Kako Y, Lutz EP. Responses to eating: lipoproteins, lipolytic products and atherosclerosis. Curr. Opin. Lipidol., 11, 235-241 (2000)

8) Zilversmit DB. Atherogenesis: a postprandial phenomenon. Circulation, 60, 473-485 (1979).

9) Boquist S, Ruotolo G, Tang R, Bjorkegren J, Bond MG, de Faire U, Karpe F, Hamsten A. Alimentary lipemia, postprandial triglyceriderich lipoproteins, and common carotid intima-media thickness in healthy, middle-aged men. Circulation, 100, 723-728 (1999).

10) Malloy MJ, Kane JP. Hyperlipidemia and cardiovascular disease. 
Curr. Opin. Lipidol., 23, 591-592 (2012).

11) Diffenderfer MR, Schaefer EJ. The composition and metabolism of large and small LDL. Curr. Opin. Lipidol., 25, 221-226 (2014).

12) Hussain MM. A proposed model for the assembly of chylomicrons. Atherosclerosis, 148, 1-15 (2000).

13) Hamilton RL, Wong JS, Cham CM, Nielsen LB, Young SG. Chylomicron-sized lipid particles are formed in the setting of apolipoprotein B deficiency. J. Lipid Res., 39, 1543-1557 (1998).

14) Shelness GS, Sellers JA. Very-low-density lipoprotein assembly and secretion. Curr. Opin. Lipidol., 12, 151-157 (2001).

15) Mansbach CM 2nd, Nevin P. Intracellular movement of triacylglycerols in the intestine. J. Lipid Res., 39, 963-968 (1998).

16) Gregg RE, Wetterau JR. The molecular basis of a betalipoproteinemia. Curr. Opin. Lipidol., 5, 81-86 (1994).

17) Sharp D, Blinderman L, Combs KA, Kienzle B, Ricci B, WagerSmith K, Gil CM, Turck CW, Bouma ME, Rader DJ, Aggerbeck LP, Gregg RE, Gordon DA, Wetterau JR. Cloning and gene defects in microsomal triglyceride transfer protein associated with abetalipoproteinaemia. Nature, 365, 65-69 (1993).

18) Wetterau JR, Aggerbeck LP, Bouma ME, Eisenberg C, Munck A, Hermier M, Schmitz J, Gay G, Rader DJ, Gregg RE. Absence of microsomal triglyceride transfer protein in individuals with a betalipoproteinemia. Science, 258, 999-1001 (1992).

19) Gordon DA, Jamil H. Progress towards understanding the role of microsomal triglyceride transfer protein in apolipoprotein-B lipoprotein assembly. Biochim. Biophys. Acta, 1486, 72-83 (2000).

20) Levy E, Marcel Y, Deckelbaum RJ, Milne R, Lepage G, Seidman E, Bendayan M, Roy CC. Intestinal apoB synthesis, lipids, and lipoproteins in chylomicron retention disease. J. Lipid Res., 28, 1263-1274 (1987).

21) Roy CC, Levy E, Green PH, Sniderman A, Letarte J, Buts JP, Orquin J, Brochu P, Weber AM, Morin CL, Marcel Y, Deckelbaum RJ. Malabsorption, hypocholesterolemia, and fat-filled enterocytes with increased intestinal apoprotein B. Chylomicron retention disease. Gastroenterology, 92, 390-399 (1987).

22) Patel S, Pessah M, Beucler I, Navarro J, Infante R. Chylomicron retention disease: exclusion of apolipoprotein $\mathrm{B}$ gene defects and detection of mRNA editing in an affected family. Atherosclerosis, 108, 201-207 (1994).

23) Jones B, Jones EL, Bonney SA, Patel HN, Mensenkamp AR, Eichenbaum-Voline S, Rudling M, Myrdal U, Annesi G, Naik S, Meadows N, Quattrone A, Islam SA, Naoumova RP, Angelin B, Infante R, Levy E, Roy CC, Freemont PS, Scott J, Shoulders CC. Mutations in a Sarl GTPase of COPII vesicles are associated with lipid absorption disorders. Nat. Genet., 34, 29-31 (2003).

24) Raal FJ, Santos RD, Blom DJ, Marais AD, Charng MJ, Cromwell WC, Lachmann RH, Gaudet D, Tan JL, Chasan-Taber S, Tribble DL, Flaim JD, Crooke ST. Mipomersen, an apolipoprotein B synthesis inhibitor, for lowering of LDL cholesterol concentrations in patients with homozygous familial hypercholesterolaemia: a randomised, double-blind, placebo-controlled trial. Lancet, 375, 998-1006 (2010).

25) Stein EA, Dufour R, Gagne C, Gaudet D, East C, Donovan JM, Chin W, Tribble DL, McGowan M. Apolipoprotein B synthesis inhibition with mipomersen in heterozygous familial hypercholesterolemia: results of a randomized, double-blind, placebo-controlled trial to assess efficacy and safety as add-on therapy in patients with coronary artery disease. Circulation, 126, 2283-2292 (2012).

26) Cuchel M, Meagher EA, du Toit Theron H, Blom DJ, Marais AD, Hegele RA, Averna MR, Sirtori CR, Shah PK, Gaudet D, Stefanutti C, Vigna GB, Du Plessis AM, Propert KJ, Sasiela WJ, Bloedon LT, Rader DJ, Phase 3 HoFH Lomitapide Study Investigators. Efficacy and safety of a microsomal triglyceride transfer protein inhibitor in patients with homozygous familial hypercholesterolaemia: a singlearm, open-label, phase 3 study. Lancet, 381, 40-46 (2013).

27) Goldberg IJ. Lipoprotein lipase and lipolysis: central roles in lipo- protein metabolism and atherogenesis. J. Lipid Res., 37, 693-707 (1996).

28) Potts JL, Fisher RM, Humphreys SM, Coppack SW, Gibbons GF, Frayn KN. Peripheral triacylglycerol extraction in the fasting and post-prandial states. Clin. Sci., 81, 621-626 (1991).

29) Ginsberg HN. Lipoprotein metabolism and its relationship to atherosclerosis. Med. Clin. North Am., 78, 1-20 (1994).

30) Peterson J, Bihain BE, Bengtsson-Olivecrona G, Deckelbaum RJ, Carpentier YA, Olivecrona T. Fatty acid control of lipoprotein lipase: a link between energy metabolism and lipid transport. Proc. Natl. Acad. Sci. U.S.A., 87, 909-913 (1990).

31) Goldberg IJ, Merkel M. Lipoprotein lipase: physiology, biochemistry, and molecular biology. Front. Biosci., 6, d388-d405 (2001).

32) Yokoyama S. A potential screening factor for accumulation of cholesteyl ester transfer protein deficiency in East Asia: Schistosoma japonicum. Biochim. Biophys. Acta, 1841, 495-504 (2014).

33) Tornvall P, Olivecrona G, Karpe F, Hamsten A, Olivecrona T. Lipoprotein lipase mass and activity in plasma and their increase after heparin are separate parameters with different relations to plasma lipoproteins. Arterioscler. Thromb. Vasc. Biol., 15, 1086-1093 (1995).

34) Cooper AD. Hepatic uptake of chylomicron remnants. J. Lipid Res., 38, 2173-2192 (1997).

35) Deckelbaum RJ, Ramakrishnan R, Eisenberg S, Olivecrona T, Bengtsson-Olivecrona G. Triacylglycerol and phospholipid hydrolysis in human plasma lipoproteins: role of lipoprotein and hepatic lipase. Biochemistry, 31, 8544-8551 (1992).

36) Sanan DA, Fan J, Bensadoun A, Taylor JM. Hepatic lipase is abundant on both hepatocyte and endothelial cell surfaces in the liver. $J$. Lipid Res., 38, 1002-1013 (1997).

37) Parthasarathy S. Lipolysis needed for chylomicron uptake? Arterioscler. Thromb. Vasc. Biol., 30, 5-6 (2010).

38) Beigneux AP, Davies BS, Gin P, Weinstein MM, Farber E, Qiao X, Peale F, Bunting S, Walzem RL, Wong JS, Blaner WS, Ding ZM, Melford K, Wongsiriroj N, Shu X, de Sauvage F, Ryan RO, Fong LG, Bensadoun A, Young SG. Glycosylphosphatidylinositolanchored high-density lipoprotein-binding protein 1 plays a critical role in the lipolytic processing of chylomicrons. Cell Metab., 5, 279-291 (2007).

39) Weinstein MM, Yin L, Tu Y, Wang X, Wu X, Castellani LW, Walzem RL, Lusis AJ, Fong LG, Beigneux AP, Young SG. Chylomicronemia elicits atherosclerosis in mice-brief report. Arterioscler. Thromb. Vasc. Biol., 30, 20-23 (2010).

40) Beigneux AP, Franssen R, Bensadoun A, Gin P, Melford K, Peter J, Walzem RL, Weinstein MM, Davies BS, Kuivenhoven JA, Kastelein JJ, Fong LG, Dallinga-Thie GM, Young SG. Chylomicronemia with a mutant GPIHBP1 (Q115P) that cannot bind lipoprotein lipase. Arterioscler. Thromb. Vasc. Biol., 29, 956-962 (2009).

41) Fraser R, Dobbs BR, Rogers GW. Lipoproteins and the liver sieve: the role of the fenestrated sinusoidal endothelium in lipoprotein metabolism, atherosclerosis, and cirrhosis. Hepatology, 21, 863-874 (1995).

42) Ji ZS, Fazio S, Lee YL, Mahley RW. Secretion-capture role for apolipoprotein $\mathrm{E}$ in remnant lipoprotein metabolism involving cell surface heparan sulfate proteoglycans. J. Biol. Chem., 269, 2764-2772 (1994).

43) Vilaró S, Ramírez I, Bengtsson-Olivecrona G, Olivecrona T, Llobera M. Lipoprotein lipase in liver. Release by heparin and immunocytochemical localization. Biochim. Biophys. Acta, 959, 106-117 (1988).

44) Mortimer BC, Beveridge DJ, Martins IJ, Redgrave TG. Intracellular localization and metabolism of chylomicron remnants in the livers of low density lipoprotein receptor-deficient mice and apoEdeficient mice. Evidence for slow metabolism via an alternative apoE-dependent pathway. J. Biol. Chem., 270, 28767-28776 (1995). 45) Rohlmann A, Gotthardt M, Hammer RE, Herz J. Inducible inactiva- 
tion of hepatic LRP gene by cre-mediated recombination confirms role of LRP in clearance of chylomicron remnants. J. Clin. Invest., 101, 689-695 (1998).

46) Jong MC, Hofker MH, Havekes LM. Role of ApoCs in lipoprotein metabolism: functional differences between ApoC1, ApoC2, and ApoC3. Arterioscler. Thromb. Vasc. Biol., 19, 472-484 (1999).

47) Proctor SD, Vine DF, Mamo JC. Arterial retention of apolipoprotein $\mathrm{B}(48)$ - and $\mathrm{B}(100)$-containing lipoproteins in atherogenesis. Curr. Opin. Lipidol., 13, 461-470 (2002).

48) Skålén K, Gustafsson M, Rydberg EK, Hulten LM, Wiklund O, Innerarity TL, Boren J. Subendothelial retention of atherogenic lipoproteins in early atherosclerosis. Nature, 417, 750-754 (2002).

49) Tabas I, Williams KJ, Boren J. Subendothelial lipoprotein retention as the initiating process in atherosclerosis: update and therapeutic implications. Circulation, 116, 1832-1844 (2007).

50) Kinnunen PK, Holopainen JM. Sphingomyelinase activity of LDL: a link between atherosclerosis, ceramide, and apoptosis? Trends Cardiovasc. Med., 12, 37-42 (2002).

51) Glass CK, Witztum JL. Atherosclerosis. the road ahead. Cell, 104, 503-516 (2001).

52) Simionescu M, Simionescu N. Proatherosclerotic events: pathobiochemical changes occurring in the arterial wall before monocyte migration. FASEB J., 7, 1359-1366 (1993).

53) Nordestgaard BG, Wootton R, Lewis B. Selective retention of VLDL, IDL, and LDL in the arterial intima of genetically hyperlipidemic rabbits in vivo. Molecular size as a determinant of fractional loss from the intima-inner media. Arterioscler. Thromb. Vasc. Biol., 15, 534-542 (1995).

54) Ö̈rni K, Pentikäinen MO, Ala-Korpela M, Kovanen PT. Aggregation, fusion, and vesicle formation of modified low density lipoprotein particles: molecular mechanisms and effects on matrix interactions. J. Lipid Res., 41, 1703-1714 (2000).

55) Pillarisetti S. Lipoprotein modulation of subendothelial heparan sulfate proteoglycans (perlecan) and atherogenicity. Trends Cardiovasc. Med., 10, 60-65 (2000).

56) Borén J, Olin K, Lee I, Chait A, Wight TN, Innerarity TL. Identification of the principal proteoglycan-binding site in LDL. A singlepoint mutation in apo-B100 severely affects proteoglycan interaction without affecting LDL receptor binding. J. Clin. Invest., 101, 2658-2664 (1998).

57) Williams KJ. Arterial wall chondroitin sulfate proteoglycans: diverse molecules with distinct roles in lipoprotein retention and atherogenesis. Curr. Opin. Lipidol., 12, 477-487 (2001).

58) Ylä-Herttuala S, Lipton BA, Rosenfeld ME, Goldberg IJ, Steinberg D, Witztum JL. Macrophages and smooth muscle cells express lipoprotein lipase in human and rabbit atherosclerotic lesions. Proc. Natl. Acad. Sci. U.S.A., 88, 10143-10147 (1991).

59) O'Brien KD, Gordon D, Deeb S, Ferguson M, Chait A. Lipoprotein lipase is synthesized by macrophage-derived foam cells in human coronary atherosclerotic plaques. J. Clin. Invest., 89, 1544-1550 (1992).

60) Hevonoja T, Pentikainen MO, Hyvonen MT, Kovanen PT, Ala-Korpela M. Structure of low density lipoprotein (LDL) particles: basis for understanding molecular changes in modified LDL. Biochim. Biophys. Acta, 1488, 189-210 (2000).

61) Ö̈rni K, Hakala JK, Annila A, Ala-Korpela M, Kovanen PT. Sphingomyelinase induces aggregation and fusion, but phospholipase A2 only aggregation, of low density lipoprotein (LDL) particles. Two distinct mechanisms leading to increased binding strength of LDL to human aortic proteoglycans. J. Biol. Chem., 273, 29127-29134 (1998).

62) Jessup W, Kritharides L. Metabolism of oxidized LDL by macrophages. Curr. Opin. Lipidol., 11, 473-481 (2000).

63) Cheng XW, Huang Z, Kuzuya M, Okumura K, Murohara T. Cysteine protease cathepsins in atherosclerosis-based vascular disease and its complications. Hypertension, 58, 978-986 (2011).
64) van der Hoek YY, Sangrar W, Cote GP, Kastelein JJ, Koschinsky ML. Binding of recombinant apolipoprotein(a) to extracellular matrix proteins. Arterioscler. Thromb., 14, 1792-1798 (1994).

65) Tsimikas S, Brilakis ES, Miller ER, McConnell JP, Lennon RJ, Kornman KS, Witztum JL, Berger PB. Oxidized phospholipids, Lp(a) lipoprotein, and coronary artery disease. N. Engl. J. Med., 353, 46-57 (2005)

66) Tsimikas S, Hall JL. Lipoprotein(a) as a potential causal genetic risk factor of cardiovascular disease: a rationale for increased efforts to understand its pathophysiology and develop targeted therapies. J. Am. Coll. Cardiol., 60, 716-721 (2012).

67) Anber V, Griffin BA, McConnell M, Packard CJ, Shepherd J. Influence of plasma lipid and LDL-subfraction profile on the interaction between low density lipoprotein with human arterial wall proteoglycans. Atherosclerosis, 124, 261-271 (1996).

68) Curtiss LK, Boisvert WA. Apolipoprotein E and atherosclerosis. Curr. Opin. Lipidol., 11, 243-251 (2000).

69) Tabas I. Secretory sphingomyelinase. Chem. Phys. Lipids, 102, 123-130 (1999).

70) Allahverdian S, Pannu PS, Francis GA. Contribution of monocytederived macrophages and smooth muscle cells to arterial foam cell formation. Cardiovasc. Res., 95, 165-172 (2012).

71) Ylä-Herttuala S, Palinski W, Rosenfeld ME, Parthasarathy S, Carew TE, Butler S, Witztum JL, Steinberg D. Evidence for the presence of oxidatively modified low density lipoprotein in atherosclerotic lesions of rabbit and man. J. Clin. Invest., 84, 1086-1095 (1989).

72) $\overline{\mathrm{Li}} \mathrm{AC}$, Glass CK. The macrophage foam cell as a target for therapeutic intervention. Nat. Med., 8, 1235-1242 (2002).

73) Botham KM, Moore EH, De Pascale C, Bejta F. The induction of macrophage foam cell formation by chylomicron remnants. Biochem. Soc. Trans., 35, 454-458 (2007).

74) Xu XX, Tabas I. Sphingomyelinase enhances low density lipoprotein uptake and ability to induce cholesteryl ester accumulation in macrophages. J. Biol. Chem., 266, 24849-24858 (1991).

75) Suits AG, Chait A, Aviram M, Heinecke JW. Phagocytosis of aggregated lipoprotein by macrophages: low density lipoprotein receptordependent foam-cell formation. Proc. Natl. Acad. Sci. U.S.A., 86, 2713-2717 (1989).

76) Haberland ME, Mottino G, Le M, Frank JS. Sequestration of aggregated LDL by macrophages studied with freeze-etch electron microscopy. J. Lipid Res., 42, 605-619 (2001).

77) Brown ML, Ramprasad MP, Umeda PK, Tanaka A, Kobayashi Y, Watanabe T, Shimoyamada H, Kuo WL, Li R, Song R, Bradley WA, Gianturco SH. A macrophage receptor for apolipoprotein B48: cloning, expression, and atherosclerosis. Proc. Natl. Acad. Sci. U.S.A., 97, 7488-7493 (2000).

78) Steinbrecher UP. Receptors for oxidized low density lipoprotein. Biochim. Biophys. Acta, 1436, 279-298 (1999).

79) Llorente-Cortés V, Martínez-González J, Badimon L. LDL receptor-related protein mediates uptake of aggregated LDL in human vascular smooth muscle cells. Arterioscler. Thromb. Vasc. Biol., 20, 1572-1579 (2000).

80) Kruth HS. Sequestration of aggregated low-density lipoproteins by macrophages. Curr. Opin. Lipidol., 13, 483-488 (2002).

81) Sakr SW, Eddy RJ, Barth H, Wang F, Greenberg S, Maxfield FR, Tabas I. The uptake and degradation of matrix-bound lipoproteins by macrophages require an intact actin Cytoskeleton, Rho family GTPases, and myosin ATPase activity. J. Biol. Chem., 276, 3764937658 (2001).

82) Tabas I. Consequences of cellular cholesterol accumulation: basic concepts and physiological implications. J. Clin. Invest., 110, 905911 (2002).

83) Yu XH, Jiang N, Yao PB, Zheng XL, Cayabyab FS, Tang CK. NPC1, intracellular cholesterol trafficking and atherosclerosis. Clin. Chim. Acta, 429, 69-75 (2014). 
84) Peake KB, Vance JE. Defective cholesterol trafficking in NiemannPick C-deficient cells. FEBS Lett., 584, 2731-2739 (2010).

85) Napoli C. Oxidation of LDL, atherogenesis, and apoptosis. Ann. $N$. Y. Acad. Sci., 1010, 698-709 (2003).

86) Tabas I. Consequences and therapeutic implications of macrophage apoptosis in atherosclerosis: the importance of lesion stage and phagocytic efficiency. Arterioscler. Thromb. Vasc. Biol., 25, 22552264 (2005).

87) Tabas I. Apoptosis and plaque destabilization in atherosclerosis: the role of macrophage apoptosis induced by cholesterol. Cell Death Differ., 11 (Suppl. 1), S12-S16 (2004).

88) Liu J, Thewke DP, Su YR, Linton MF, Fazio S, Sinensky MS. Reduced macrophage apoptosis is associated with accelerated atherosclerosis in low-density lipoprotein receptor-null mice. Arterioscler. Thromb. Vasc. Biol., 25, 174-179 (2005).

89) Arai S, Shelton JM, Chen M, Bradley MN, Castrillo A, Bookout AL, Mak PA, Edwards PA, Mangelsdorf DJ, Tontonoz P, Miyazaki T. A role for the apoptosis inhibitory factor AIM/Spalpha/Api6 in atherosclerosis development. Cell Metab., 1, 201-213 (2005).

90) Kellner-Weibel G, Geng YJ, Rothblat GH. Cytotoxic cholesterol is generated by the hydrolysis of cytoplasmic cholesteryl ester and transported to the plasma membrane. Atherosclerosis, 146, 309-319 (1999).

91) Feng B, Yao PM, Li Y, Devlin CM, Zhang D, Harding HP, Sweeney M, Rong JX, Kuriakose G, Fisher EA, Marks AR, Ron D, Tabas I. The endoplasmic reticulum is the site of cholesterol-induced cytotoxicity in macrophages. Nat. Cell Biol., 5, 781-792 (2003).

92) Lupu F, Danaricu I, Simionescu N. Development of intracellular lipid deposits in the lipid-laden cells of atherosclerotic lesions. A cytochemical and ultrastructural study. Atherosclerosis, 67, 127-142 (1987).

93) Colles SM, Irwin KC, Chisolm GM. Roles of multiple oxidized LDL lipids in cellular injury: dominance of 7 beta-hydroperoxycholesterol. J. Lipid Res., 37, 2018-2028 (1996).

94) Salvayre R, Auge N, Benoist H, Negre-Salvayre A. Oxidized lowdensity lipoprotein-induced apoptosis. Biochim. Biophys. Acta, 1585, 213-221 (2002).

95) Chan L, Chang BH, Nakamuta M, Li WH, Smith LC. Apobec-1 and apolipoprotein B mRNA editing. Biochim. Biophys. Acta, 1345, 11-26 (1997).

96) Esser V, Limbird LE, Brown MS, Goldstein JL, Russell DW. Mutational analysis of the ligand binding domain of the low density lipoprotein receptor. J. Biol. Chem., 263, 13282-13290 (1988).

97) Yang CY, Gu ZW, Weng SA, Kim TW, Chen SH, Pownall HJ, Sharp PM, Liu SW, Li WH, Gotto AM Jr, Chan L. Structure of apolipoprotein B-100 of human low density lipoproteins. Arteriosclerosis, 9, 96-108 (1989).

98) Taniguchi T, Ishikawa Y, Tsunemitsu M, Fukuzaki H. The structures of the asparagine-linked sugar chains of human apolipoprotein B-100. Arch. Biochem. Biophys., 273, 197-205 (1989).

99) Morita SY, Kawabe M, Nakano M, Handa T. Pluronic L81 affects the lipid particle sizes and apolipoprotein B conformation. Chem. Phys. Lipids, 126, 39-48 (2003).

100) Wang L, Small DM. Interfacial properties of amphipathic beta strand consensus peptides of apolipoprotein B at oil/water interfaces. J. Lipid Res., 45, 1704-1715 (2004).

101) Wang L, Walsh MT, Small DM. Apolipoprotein B is conformationally flexible but anchored at a triolein/water interface: a possible model for lipoprotein surfaces. Proc. Natl. Acad. Sci. U.S.A., 103, 6871-6876 (2006).

102) Chatterton JE, Phillips ML, Curtiss LK, Milne R, Fruchart JC, Schumaker VN. Immunoelectron microscopy of low density lipoproteins yields a ribbon and bow model for the conformation of apolipoprotein B on the lipoprotein surface. J. Lipid Res., 36, 2027-2037 (1995).

103) Rava P, Ojakian GK, Shelness GS, Hussain MM. Phospholipid transfer activity of microsomal triacylglycerol transfer protein is sufficient for the assembly and secretion of apolipoprotein B lipoproteins. J. Biol. Chem., 281, 11019-11027 (2006).

104) Schumaker VN, Phillips ML, Chatterton JE. Apolipoprotein B and low-density lipoprotein structure: implications for biosynthesis of triglyceride-rich lipoproteins. Adv. Protein Chem., 45, 205-248 (1994).

105) Innerarity TL, Mahley RW, Weisgraber KH, Bersot TP, Krauss RM, Vega GL, Grundy SM, Friedl W, Davignon J, McCarthy BJ. Familial defective apolipoprotein B-100: a mutation of apolipoprotein B that causes hypercholesterolemia. J. Lipid Res., 31, 1337-1349 (1990).

106) Pullinger CR, Hennessy LK, Chatterton JE, Liu W, Love JA, Mendel CM, Frost PH, Malloy MJ, Schumaker VN, Kane JP. Familial ligand-defective apolipoprotein B. Identification of a new mutation that decreases LDL receptor binding affinity. J. Clin. Invest., 95, 1225-1234 (1995).

107) Law A, Scott J. A cross-species comparison of the apolipoprotein B domain that binds to the LDL receptor. J. Lipid Res., 31, 1109-1120 (1990).

108) Boren J, Lee I, Zhu W, Arnold K, Taylor S, Innerarity TL. Identification of the low density lipoprotein receptor-binding site in apolipoprotein B100 and the modulation of its binding activity by the carboxyl terminus in familial defective apo-B100. J. Clin. Invest., 101, 1084-1093 (1998).

109) Goldberg IJ, Wagner WD, Pang L, Paka L, Curtiss LK, DeLozier JA, Shelness GS, Young CS, Pillarisetti S. The NH2-terminal region of apolipoprotein B is sufficient for lipoprotein association with glycosaminoglycans. J. Biol. Chem., 273, 35355-35361 (1998).

110) Flood C, Gustafsson M, Richardson PE, Harvey SC, Segrest JP, Boren J. Identification of the proteoglycan binding site in apolipoprotein B48. J. Biol. Chem., 277, 32228-32233 (2002).

111) Saito H, Lund-Katz S, Phillips MC. Contributions of domain structure and lipid interaction to the functionality of exchangeable human apolipoproteins. Prog. Lipid Res., 43, 350-380 (2004).

112) Weisgraber KH. Apolipoprotein E: structure-function relationships. Adv. Protein Chem., 45, 249-302 (1994).

113) Segrest JP, De Loof H, Dohlman JG, Brouillette CG, Anantharamaiah GM. Amphipathic helix motif: classes and properties. Proteins, 8, 103-117 (1990).

114) Funahashi T, Yokoyama S, Yamamoto A. Association of apolipoprotein $\mathrm{E}$ with the low density lipoprotein receptor: demonstration of its co-operativity on lipid microemulsion particles. J. Biochem., 105, 582-587 (1989).

115) Sakamoto T, Tanaka M, Vedhachalam C, Nickel M, Nguyen D, Dhanasekaran P, Phillips MC, Lund-Katz S, Saito H. Contributions of the carboxyl-terminal helical segment to the self-association and lipoprotein preferences of human apolipoprotein E3 and E4 isoforms. Biochemistry, 47, 2968-2977 (2008).

116) Wilson C, Wardell MR, Weisgraber KH, Mahley RW, Agard DA. Three-dimensional structure of the LDL receptor-binding domain of human apolipoprotein E. Science, 252, 1817-1822 (1991).

117) Croy JE, Brandon T, Komives EA. Two apolipoprotein E mimetic peptides, ApoE(130-149) and ApoE(141-155)2, bind to LRP1. Biochemistry, 43, 7328-7335 (2004).

118) Guttman M, Prieto JH, Handel TM, Domaille PJ, Komives EA. Structure of the minimal interface between ApoE and LRP. J. Mol. Biol., 398, 306-319 (2010).

119) Saito H, Dhanasekaran P, Nguyen D, Baldwin F, Weisgraber KH, Wehrli S, Phillips MC, Lund-Katz S. Characterization of the heparin binding sites in human apolipoprotein E. J. Biol. Chem., 278, 14782-14787 (2003).

120) Sivashanmugam A, Wang J. A unified scheme for initiation and conformational adaptation of human apolipoprotein E N-terminal domain upon lipoprotein binding and for receptor binding activity. J. Biol. Chem., 284, 14657-14666 (2009). 
121) Lund-Katz S, Zaiou M, Wehrli S, Dhanasekaran P, Baldwin F, Weisgraber KH, Phillips MC. Effects of lipid interaction on the lysine microenvironments in apolipoprotein E. J. Biol. Chem., 275, 34459-34464 (2000).

122) Lund-Katz S, Wehrli S, Zaiou M, Newhouse Y, Weisgraber KH, Phillips MC. Effects of polymorphism on the microenvironment of the LDL receptor-binding region of human apoE. J. Lipid Res., 42, 894-901 (2001).

123) Yamamoto T, Ryan RO. Role of leucine zipper motif in apoE3 Nterminal domain lipid binding activity. Biochim. Biophys. Acta, 1761, 1100-1106 (2006).

124) Narayanaswami V, Ryan RO. Molecular basis of exchangeable apolipoprotein function. Biochim. Biophys. Acta, 1483, 15-36 (2000).

125) Schaefer EJ, Gregg RE, Ghiselli G, Forte TM, Ordovas JM, Zech LA, Brewer HB Jr. Familial apolipoprotein E deficiency. J. Clin. Invest., 78, 1206-1219 (1986).

126) Zhang SH, Reddick RL, Piedrahita JA, Maeda N. Spontaneous hypercholesterolemia and arterial lesions in mice lacking apolipoprotein E. Science, 258, 468-471 (1992).

127) Plump AS, Smith JD, Hayek T, Aalto-Setala K, Walsh A, Verstuyft JG, Rubin EM, Breslow JL. Severe hypercholesterolemia and atherosclerosis in apolipoprotein E-deficient mice created by homologous recombination in ES cells. Cell, 71, 343-353 (1992).

128) Ylä-Herttuala S, Jaakkola O, Ehnholm C, Tikkanen MJ, Solakivi T, Sarkioja T, Nikkari T. Characterization of two lipoproteins containing apolipoproteins B and E from lesion-free human aortic intima. J. Lipid Res., 29, 563-572 (1988).

129) Perrey S, Ishibashi S, Kitamine T, Osuga J, Yagyu H, Chen $Z$, Shionoiri F, Iizuka Y, Yahagi N, Tamura Y, Ohashi K, Harada K, Gotoda T, Yamada N. The LDL receptor is the major pathway for beta-VLDL uptake by mouse peritoneal macrophages. Atherosclerosis, 154, 51-60 (2001).

130) Fazio S, Babaev VR, Murray AB, Hasty AH, Carter KJ, Gleaves LA, Atkinson JB, Linton MF. Increased atherosclerosis in mice reconstituted with apolipoprotein E null macrophages. Proc. Natl. Acad. Sci. U.S.A., 94, 4647-4652 (1997).

131) Willnow TE. Mechanisms of hepatic chylomicron remnant clearance. Diabet. Med., 14 (Suppl. 3), S75-S80 (1997).

132) Innerarity TL, Weisgraber KH, Arnold KS, Rall SC Jr, Mahley RW. Normalization of receptor binding of apolipoprotein E2. Evidence for modulation of the binding site conformation. J. Biol. Chem., 259, 7261-7267 (1984).

133) Dong LM, Parkin S, Trakhanov SD, Rupp B, Simmons T, Arnold KS, Newhouse YM, Innerarity TL, Weisgraber KH. Novel mechanism for defective receptor binding of apolipoprotein E2 in type III hyperlipoproteinemia. Nat. Struct. Biol., 3, 718-722 (1996).

134) Ji ZS, Fazio S, Mahley RW. Variable heparan sulfate proteoglycan binding of apolipoprotein $\mathrm{E}$ variants may modulate the expression of type III hyperlipoproteinemia. J. Biol. Chem., 269, 13421-13428 (1994).

135) Strittmatter WJ, Saunders AM, Schmechel D, Pericak-Vance M, Enghild J, Salvesen GS, Roses AD. Apolipoprotein E: high-avidity binding to beta-amyloid and increased frequency of type 4 allele in late-onset familial Alzheimer disease. Proc. Natl. Acad. Sci. U.S.A., 90, 1977-1981 (1993).

136) Corder EH, Saunders AM, Strittmatter WJ, Schmechel DE, Gaskell PC, Small GW, Roses AD, Haines JL, Pericak-Vance MA. Gene dose of apolipoprotein E type 4 allele and the risk of Alzheimer's disease in late onset families. Science, 261, 921-923 (1993).

137) Kowal RC, Herz J, Weisgraber KH, Mahley RW, Brown MS, Goldstein JL. Opposing effects of apolipoproteins E and C on lipoprotein binding to low density lipoprotein receptor-related protein. $J$. Biol. Chem., 265, 10771-10779 (1990).

138) Sehayek E, Eisenberg S. Mechanisms of inhibition by apolipoprotein $\mathrm{C}$ of apolipoprotein E-dependent cellular metabolism of human triglyceride-rich lipoproteins through the low density lipoprotein receptor pathway. J. Biol. Chem., 266, 18259-18267 (1991).

139) Jong MC, Dahlmans VE, Hofker MH, Havekes LM. Nascent verylow-density lipoprotein triacylglycerol hydrolysis by lipoprotein lipase is inhibited by apolipoprotein E in a dose-dependent manner. Biochem. J., 328, 745-750 (1997).

140) Huang Y, Liu XQ, Rall SC Jr, Taylor JM, von Eckardstein A, Assmann G, Mahley RW. Overexpression and accumulation of apolipoprotein E as a cause of hypertriglyceridemia. J. Biol. Chem., 273, 26388-26393 (1998).

141) Gómez-Coronado D, Sáez GT, Lasunción MA, Herrera E. Different hydrolytic efficiencies of adipose tissue lipoprotein lipase on verylow-density lipoprotein subfractions separated by heparin-Sepharose chromatography. Biochim. Biophys. Acta, 1167, 70-78 (1993).

142) Rensen PC, van Berkel TJ. Apolipoprotein E effectively inhibits lipoprotein lipase-mediated lipolysis of chylomicron-like triglyceride-rich lipid emulsions in vitro and in vivo. J. Biol. Chem., 271, 14791-14799 (1996).

143) Rozek A, Buchko GW, Cushley RJ. Conformation of two peptides corresponding to human apolipoprotein C-I residues 7-24 and $35-53$ in the presence of sodium dodecyl sulfate by CD and NMR spectroscopy. Biochemistry, 34, 7401-7408 (1995).

144) Shachter NS. Apolipoproteins C-I and C-III as important modulators of lipoprotein metabolism. Curr. Opin. Lipidol., 12, 297-304 (2001).

145) Weisgraber KH, Mahley RW, Kowal RC, Herz J, Goldstein JL, Brown MS. Apolipoprotein C-I modulates the interaction of apolipoprotein $\mathrm{E}$ with beta-migrating very low density lipoproteins (beta-VLDL) and inhibits binding of beta-VLDL to low density lipoprotein receptor-related protein. J. Biol. Chem., 265, 22453-22459 (1990).

146) Steyrer E, Kostner GM. Activation of lecithin-cholesterol acyltransferase by apolipoprotein D: comparison of proteoliposomes containing apolipoprotein D, A-I or C-I. Biochim. Biophys. Acta, 958, 484-491 (1988)

147) Sparks DL, Pritchard PH. Transfer of cholesteryl ester into high density lipoprotein by cholesteryl ester transfer protein: effect of HDL lipid and apoprotein content. J. Lipid Res., 30, 1491-1498 (1989).

148) Gautier T, Masson D, de Barros JP, Athias A, Gambert P, Aunis D, Metz-Boutigue MH, Lagrost L. Human apolipoprotein C-I accounts for the ability of plasma high density lipoproteins to inhibit the cholesteryl ester transfer protein activity. J. Biol. Chem., 275, 37504-37509 (2000)

149) Shachter NS, Ebara T, Ramakrishnan R, Steiner G, Breslow JL, Ginsberg HN, Smith JD. Combined hyperlipidemia in transgenic mice overexpressing human apolipoprotein Cl. J. Clin. Invest., 98, 846-855 (1996).

150) Jong MC, Dahlmans VE, van Gorp PJ, van Dijk KW, Breuer ML, Hofker MH, Havekes LM. In the absence of the low density lipoprotein receptor, human apolipoprotein $\mathrm{Cl}$ overexpression in transgenic mice inhibits the hepatic uptake of very low density lipoproteins via a receptor-associated protein-sensitive pathway. J. Clin. Invest., 98, 2259-2267 (1996).

151) van Ree JH, Hofker MH, van den Broek WJ, van Deursen JM, van der Boom H, Frants RR, Wieringa B, Havekes LM. Increased response to cholesterol feeding in apolipoprotein C1-deficient mice. Biochem. J., 305, 905-911 (1995).

152) Zdunek J, Martinez GV, Schleucher J, Lycksell PO, Yin Y, Nilsson S, Shen Y, Olivecrona G, Wijmenga S. Global structure and dynamics of human apolipoprotein CII in complex with micelles: evidence for increased mobility of the helix involved in the activation of lipoprotein lipase. Biochemistry, 42, 1872-1889 (2003).

153) Shen Y, Lookene A, Zhang L, Olivecrona G. Site-directed mutagenesis of apolipoprotein CII to probe the role of its secondary structure for activation of lipoprotein lipase. J. Biol. Chem., 285, 7484-7492 (2010). 
154) Olivecrona G, Beisiegel U. Lipid binding of apolipoprotein CII is required for stimulation of lipoprotein lipase activity against apolipoprotein CII-deficient chylomicrons. Arterioscler. Thromb. Vasc. Biol., 17, 1545-1549 (1997).

155) Landis BA, Rotolo FS, Meyers WC, Clark AB, Quarfordt SH. Influence of apolipoprotein $\mathrm{E}$ on soluble and heparin-immobilized hepatic lipase. Am. J. Physiol., 252, G805-G810 (1987).

156) Nishida HI, Nakanishi T, Yen EA, Arai H, Yen FT, Nishida T. Nature of the enhancement of lecithin-cholesterol acyltransferase reaction by various apolipoproteins. J. Biol. Chem., 261, 12028-12035 (1986).

157) Breckenridge WC, Little JA, Steiner G, Chow A, Poapst M. Hypertriglyceridemia associated with deficiency of apolipoprotein C-II. $N$. Engl. J. Med., 298, 1265-1273 (1978).

158) Cox DW, Breckenridge WC, Little JA. Inheritance of apolipoprotein C-II deficiency with hypertriglyceridemia and pancreatitis. N. Engl. J. Med., 299, 1421-1424 (1978).

159) Shachter NS, Hayek T, Leff T, Smith JD, Rosenberg DW, Walsh A, Ramakrishnan R, Goldberg IJ, Ginsberg HN, Breslow JL. Overexpression of apolipoprotein CII causes hypertriglyceridemia in transgenic mice. J. Clin. Invest., 93, 1683-1690 (1994).

160) Batal R, Tremblay M, Barrett PH, Jacques H, Fredenrich A, Mamer O, Davignon J, Cohn JS. Plasma kinetics of apoC-III and apoE in normolipidemic and hypertriglyceridemic subjects. J. Lipid Res., 41, 706-718 (2000).

161) Krauss RM. Atherogenicity of triglyceride-rich lipoproteins. Am. J. Cardiol., 81 (4A), 13B-17B (1998).

162) Liu H, Talmud PJ, Lins L, Brasseur R, Olivecrona G, Peelman F, Vandekerckhove J, Rosseneu M, Labeur C. Characterization of recombinant wild type and site-directed mutations of apolipoprotein C-III: lipid binding, displacement of ApoE, and inhibition of lipoprotein lipase. Biochemistry, 39, 9201-9212 (2000).

163) Gangabadage CS, Zdunek J, Tessari M, Nilsson S, Olivecrona G, Wijmenga SS. Structure and dynamics of human apolipoprotein CIII. J. Biol. Chem., 283, 17416-17427 (2008).

164) Roghani A, Zannis VI. Mutagenesis of the glycosylation site of human ApoCIII. O-linked glycosylation is not required for ApoCIII secretion and lipid binding. J. Biol. Chem., 263, 17925-17932 (1988).

165) Liu H, Labeur C, Xu CF, Ferrell R, Lins L, Brasseur R, Rosseneu M, Weiss KM, Humphries SE, Talmud PJ. Characterization of the lipid-binding properties and lipoprotein lipase inhibition of a novel apolipoprotein C-III variant Ala23Thr. J. Lipid Res., 41, 1760-1771 (2000).

166) Clavey V, Lestavel-Delattre S, Copin C, Bard JM, Fruchart JC. Modulation of lipoprotein $\mathrm{B}$ binding to the LDL receptor by exogenous lipids and apolipoproteins CI, CII, CIII, and E. Arterioscler. Thromb. Vasc. Biol., 15, 963-971 (1995).

167) Aalto-Setälä K, Fisher EA, Chen X, Chajek-Shaul T, Hayek T, Zechner R, Walsh A, Ramakrishnan R, Ginsberg HN, Breslow JL. Mechanism of hypertriglyceridemia in human apolipoprotein (apo) CIII transgenic mice. Diminished very low density lipoprotein fractional catabolic rate associated with increased apo CIII and reduced apo E on the particles. J. Clin. Invest., 90, 1889-1900 (1992).

168) Karathanasis SK. Apolipoprotein multigene family: tandem organization of human apolipoprotein AI, CIII, and AIV genes. Proc. Natl. Acad. Sci. U.S.A., 82, 6374-6378 (1985).

169) Maeda N, Li H, Lee D, Oliver P, Quarfordt SH, Osada J. Targeted disruption of the apolipoprotein C-III gene in mice results in hypotriglyceridemia and protection from postprandial hypertriglyceridemia. J. Biol. Chem., 269, 23610-23616 (1994).

170) Jong MC, Rensen PC, Dahlmans VE, van der Boom H, van Berkel TJ, Havekes LM. Apolipoprotein C-III deficiency accelerates triglyceride hydrolysis by lipoprotein lipase in wild-type and apoE knockout mice. J. Lipid Res., 42, 1578-1585 (2001).

171) Forte TM, Nichols AV, Krauss RM, Norum RA. Familial apolipo- protein AI and apolipoprotein CIII deficiency. Subclass distribution, composition, and morphology of lipoproteins in a disorder associated with premature atherosclerosis. J. Clin. Invest., 74, 1601-1613 (1984).

172) Ginsberg HN, Le NA, Goldberg IJ, Gibson JC, Rubinstein A, Wang-Iverson P, Norum R, Brown WV. Apolipoprotein B metabolism in subjects with deficiency of apolipoproteins CIII and AI. Evidence that apolipoprotein CIII inhibits catabolism of triglyceriderich lipoproteins by lipoprotein lipase in vivo. J. Clin. Invest., 78, 1287-1295 (1986).

173) Atzmon G, Rincon M, Schechter CB, Shuldiner AR, Lipton RB, Bergman A, Barzilai N. Lipoprotein genotype and conserved pathway for exceptional longevity in humans. PLoS Biol., 4, e113 (2006).

174) Petersen KF, Dufour S, Hariri A, Nelson-Williams C, Foo JN, Zhang XM, Dziura J, Lifton RP, Shulman GI. Apolipoprotein C3 gene variants in nonalcoholic fatty liver disease. N. Engl. J. Med., 362, 1082-1089 (2010).

175) Luc G, Fievet C, Arveiler D, Evans AE, Bard JM, Cambien F, Fruchart JC, Ducimetiere P. Apolipoproteins C-III and E in apoBand non-apoB-containing lipoproteins in two populations at contrasting risk for myocardial infarction: the ECTIM study. Etude Cas Temoins sur'Infarctus du Myocarde. J. Lipid Res., 37, 508-517 (1996).

176) Sacks FM, Alaupovic P, Moye LA, Cole TG, Sussex B, Stampfer MJ, Pfeffer MA, Braunwald E. VLDL, apolipoproteins B, CIII, and $\mathrm{E}$, and risk of recurrent coronary events in the Cholesterol and Recurrent Events (CARE) trial. Circulation, 102, 1886-1892 (2000).

177) Lee SJ, Campos H, Moye LA, Sacks FM. LDL containing apolipoprotein CIII is an independent risk factor for coronary events in diabetic patients. Arterioscler. Thromb. Vasc. Biol., 23, 853-858 (2003).

178) Lee SJ, Moye LA, Campos H, Williams GH, Sacks FM. Hypertriglyceridemia but not diabetes status is associated with VLDL containing apolipoprotein CIII in patients with coronary heart disease. Atherosclerosis, 167, 293-302 (2003).

179) Chan DC, Watts GF, Nguyen MN, Barrett PH. Apolipoproteins $\mathrm{C}$-III and $\mathrm{A}-\mathrm{V}$ as predictors of very-low-density lipoprotein triglyceride and apolipoprotein B-100 kinetics. Arterioscler. Thromb. Vasc. Biol., 26, 590-596 (2006).

180) Mendivil CO, Zheng C, Furtado J, Lel J, Sacks FM. Metabolism of very-low-density lipoprotein and low-density lipoprotein containing apolipoprotein C-III and not other small apolipoproteins. Arterioscler. Thromb. Vasc. Biol., 30, 239-245 (2010).

181) Zheng C, Khoo C, Furtado J, Sacks FM. Apolipoprotein C-III and the metabolic basis for hypertriglyceridemia and the dense lowdensity lipoprotein phenotype. Circulation, 121, 1722-1734 (2010).

182) Pollin TI, Damcott CM, Shen H, Ott SH, Shelton J, Horenstein RB, Post W, McLenithan JC, Bielak LF, Peyser PA, Mitchell BD, Miller M, O'Connell JR, Shuldiner AR. A null mutation in human APOC3 confers a favorable plasma lipid profile and apparent cardioprotection. Science, 322, 1702-1705 (2008).

183) de Silva HV, Lauer SJ, Wang J, Simonet WS, Weisgraber KH, Mahley RW, Taylor JM. Overexpression of human apolipoprotein C-III in transgenic mice results in an accumulation of apolipoprotein B48 remnants that is corrected by excess apolipoprotein E. J. Biol. Chem., 269, 2324-2335 (1994).

184) Masucci-Magoulas L, Goldberg IJ, Bisgaier CL, Serajuddin H, Francone OL, Breslow JL, Tall AR. A mouse model with features of familial combined hyperlipidemia. Science, 275, 391-394 (1997).

185) Yokoyama S. Apolipoprotein-mediated cellular cholesterol efflux. Biochim. Biophys. Acta, 1392, 1-15 (1998).

186) Yokoyama S. Assembly of high-density lipoprotein. Arterioscler. Thromb. Vasc. Biol., 26, 20-27 (2006).

187) Nagao K, Tomioka M, Ueda K. Function and regulation of ABCA1-membrane meso-domain organization and reorganization. 
FEBS J., 278, 3190-3203 (2011).

188) Saito H, Dhanasekaran P, Nguyen D, Holvoet P, Lund-Katz S, Phillips MC. Domain structure and lipid interaction in human apolipoproteins A-I and E, a general model. J. Biol. Chem., 278, 23227-23232 (2003).

189) McLean LR, Demel RA, Socorro L, Shinomiya M, Jackson RL. Mechanism of action of lipoprotein lipase. Methods Enzymol., 129, 738-763 (1986).

190) Tajima S, Yokoyama S, Yamamoto A. Effect of lipid particle size on association of apolipoproteins with lipid. J. Biol. Chem., 258, 10073-10082 (1983).

191) Saxena U, Klein MG, Goldberg IJ. Metabolism of endothelial cellbound lipoprotein lipase. Evidence for heparan sulfate proteoglycan-mediated internalization and recycling. J. Biol. Chem., 265, 12880-12886 (1990).

192) Merkel M, Eckel RH, Goldberg IJ. Lipoprotein lipase: genetics, lipid uptake, and regulation. J. Lipid Res., 43, 1997-2006 (2002).

193) Cruz WS, Kwon G, Marshall CA, McDaniel ML, Semenkovich CF. Glucose and insulin stimulate heparin-releasable lipoprotein lipase activity in mouse islets and INS-1 cells. A potential link between insulin resistance and beta-cell dysfunction. J. Biol. Chem., 276, 12162-12168 (2001).

194) Mulder M, Lombardi P, Jansen H, van Berkel TJ, Frants RR, Havekes LM. Heparan sulphate proteoglycans are involved in the lipoprotein lipase-mediated enhancement of the cellular binding of very low density and low density lipoproteins. Biochem. Biophys. Res. Commun., 185, 582-587 (1992).

195) Mulder M, Lombardi P, Jansen H, van Berkel TJ, Frants RR, Havekes LM. Low density lipoprotein receptor internalizes low density and very low density lipoproteins that are bound to heparan sulfate proteoglycans via lipoprotein lipase. J. Biol. Chem., 268, 9369-9375 (1993).

196) Medh JD, Bowen SL, Fry GL, Ruben S, Andracki M, Inoue I, Lalouel JM, Strickland DK, Chappell DA. Lipoprotein lipase binds to low density lipoprotein receptors and induces receptor-mediated catabolism of very low density lipoproteins in vitro. J. Biol. Chem., 271, 17073-17080 (1996).

197) Chappell DA, Fry GL, Waknitz MA, Iverius PH, Williams SE, Strickland DK. The low density lipoprotein receptor-related protein/ alpha 2-macroglobulin receptor binds and mediates catabolism of bovine milk lipoprotein lipase. J. Biol. Chem., 267, 25764-25767 (1992).

198) Arimoto I, Saito H, Kawashima Y, Miyajima K, Handa T. Effects of sphingomyelin and cholesterol on lipoprotein lipase-mediated lipolysis in lipid emulsions. J. Lipid Res., 39, 143-151 (1998).

199) Saito H, Arimoto I, Tanaka M, Sasaki T, Tanimoto T, Okada S, Handa T. Inhibition of lipoprotein lipase activity by sphingomyelin: role of membrane surface structure. Biochim. Biophys. Acta, 1486, 312-320 (2000).

200) MacPhee CE, Chan RY, Sawyer WH, Stafford WF, Howlett GJ. Interaction of lipoprotein lipase with homogeneous lipid emulsions. $J$. Lipid Res., 38, 1649-1659 (1997).

201) Heizmann C, Kirchgessner T, Kwiterovich PO, Ladias JA, Derby C, Antonarakis SE, Lusis AJ. DNA polymorphism haplotypes of the human lipoprotein lipase gene: possible association with high density lipoprotein levels. Hum. Genet., 86, 578-584 (1991).

202) Renier G, Skamene E, DeSanctis JB, Radzioch D. High macrophage lipoprotein lipase expression and secretion are associated in inbred murine strains with susceptibility to atherosclerosis. Arterioscler. Thromb., 13, 190-196 (1993).

203) Babaev VR, Patel MB, Semenkovich CF, Fazio S, Linton MF. Macrophage lipoprotein lipase promotes foam cell formation and atherosclerosis in low density lipoprotein receptor-deficient mice. $J$. Biol. Chem., 275, 26293-26299 (2000).

204) Eisenberg S, Sehayek E, Olivecrona T, Vlodavsky I. Lipoprotein lipase enhances binding of lipoproteins to heparan sulfate on cell surfaces and extracellular matrix. J. Clin. Invest., 90, 2013-2021 (1992).

205) Yamamoto T, Davis CG, Brown MS, Schneider WJ, Casey ML, Goldstein JL, Russell DW. The human LDL receptor: a cysteinerich protein with multiple Alu sequences in its mRNA. Cell, 39, 27-38 (1984).

206) Russell DW, Brown MS, Goldstein JL. Different combinations of cysteine-rich repeats mediate binding of low density lipoprotein receptor to two different proteins. J. Biol. Chem., 264, 21682-21688 (1989).

207) Santos RD, Maranhao RC. What is new in familial hypercholesterolemia? Curr. Opin. Lipidol., 25, 183-188 (2014).

208) Cohen JC, Boerwinkle E, Mosley TH Jr, Hobbs HH. Sequence variations in PCSK9, low LDL, and protection against coronary heart disease. N. Engl. J. Med., 354, 1264-1272 (2006).

209) Stein EA, Gipe D, Bergeron J, Gaudet D, Weiss R, Dufour R, Wu R, Pordy R. Effect of a monoclonal antibody to PCSK9, REGN727! SAR236553, to reduce low-density lipoprotein cholesterol in patients with heterozygous familial hypercholesterolaemia on stable statin dose with or without ezetimibe therapy: a phase 2 randomised controlled trial. Lancet, 380, 29-36 (2012).

210) Raal F, Scott R, Somaratne R, Bridges I, Li G, Wasserman SM, Stein EA. Low-density lipoprotein cholesterol-lowering effects of AMG 145, a monoclonal antibody to proprotein convertase subtilisin/kexin type 9 serine protease in patients with heterozygous familial hypercholesterolemia: the reduction of LDL-C with PCSK9 inhibition in heterozygous familial hypercholesterolemia disorder (RUTHERFORD) randomized trial. Circulation, 126, 2408-2417 (2012).

211) Herz J, Strickland DK. LRP: a multifunctional scavenger and signaling receptor. J. Clin. Invest., 108, 779-784 (2001).

212) Willnow TE, Armstrong SA, Hammer RE, Herz J. Functional expression of low density lipoprotein receptor-related protein is controlled by receptor-associated protein in vivo. Proc. Natl. Acad. Sci. U.S.A., 92, 4537-4541 (1995).

213) Willnow TE, Rohlmann A, Horton J, Otani H, Braun JR, Hammer RE, Herz J. RAP, a specialized chaperone, prevents ligand-induced ER retention and degradation of LDL receptor-related endocytic receptors. EMBO J., 15, 2632-2639 (1996).

214) Moestrup SK, Gliemann J, Pallesen G. Distribution of the alpha 2-macroglobulin receptor/low density lipoprotein receptor-related protein in human tissues. Cell Tissue Res., 269, 375-382 (1992).

215) Luoma J, Hiltunen T, Sarkioja T, Moestrup SK, Gliemann J, Kodama T, Nikkari T, Yla-Herttuala S. Expression of alpha 2-macroglobulin receptor/low density lipoprotein receptor-related protein and scavenger receptor in human atherosclerotic lesions. J. Clin. Invest., 93, 2014-2021 (1994).

216) Roskams T, Moshage H, De Vos R, Guido D, Yap P, Desmet V. Heparan sulfate proteoglycan expression in normal human liver. Hepatology, 21, 950-958 (1995).

217) Gallagher JT, Turnbull JE, Lyon M. Patterns of sulphation in heparan sulphate: polymorphism based on a common structural theme. Int. J. Biochem., 24, 553-560 (1992).

218) Iozzo RV, Cohen IR, Grassel S, Murdoch AD. The biology of perlecan: the multifaceted heparan sulphate proteoglycan of basement membranes and pericellular matrices. Biochem. J., 302, 625-639 (1994).

219) Hollmann J, Schmidt A, von Bassewitz DB, Buddecke E. Relationship of sulfated glycosaminoglycans and cholesterol content in normal and arteriosclerotic human aorta. Arteriosclerosis, 9, 154-158 (1989).

220) Jensen T. Pathogenesis of diabetic vascular disease: evidence for the role of reduced heparan sulfate proteoglycan. Diabetes, 46 (Suppl. 2), S98-S100 (1997).

221) Al-Haideri M, Goldberg IJ, Galeano NF, Gleeson A, Vogel T, Gorecki M, Sturley SL, Deckelbaum RJ. Heparan sulfate proteoglycan- 
mediated uptake of apolipoprotein E-triglyceride-rich lipoprotein particles: a major pathway at physiological particle concentrations. Biochemistry, 36, 12766-12772 (1997).

222) Ji ZS, Sanan DA, Mahley RW. Intravenous heparinase inhibits remnant lipoprotein clearance from the plasma and uptake by the liver: in vivo role of heparan sulfate proteoglycans. J. Lipid Res., 36, 583-592 (1995).

223) Ji ZS, Brecht WJ, Miranda RD, Hussain MM, Innerarity TL, Mahley RW. Role of heparan sulfate proteoglycans in the binding and uptake of apolipoprotein E-enriched remnant lipoproteins by cultured cells. J. Biol. Chem., 268, 10160-10167 (1993).

224) van Dijk MC, Ziere GJ, Boers W, Linthorst C, Bijsterbosch MK, van Berkel TJ. Recognition of chylomicron remnants and betamigrating very-low-density lipoproteins by the remnant receptor of parenchymal liver cells is distinct from the liver alpha 2-macroglobulin-recognition site. Biochem. J., 279, 863-870 (1991).

225) Ji ZS, Mahley RW. Lactoferrin binding to heparan sulfate proteoglycans and the LDL receptor-related protein. Further evidence supporting the importance of direct binding of remnant lipoproteins to HSPG. Arterioscler. Thromb., 14, 2025-2031 (1994).

226) Huettinger M, Retzek H, Eder M, Goldenberg H. Characteristics of chylomicron remnant uptake into rat liver. Clin. Biochem., 21, 87-92 (1988).

227) Merrill AH Jr, Lingrell S, Wang E, Nikolova-Karakashian M, Vales TR, Vance DE. Sphingolipid biosynthesis de novo by rat hepatocytes in culture. Ceramide and sphingomyelin are associated with, but not required for, very low density lipoprotein secretion. J. Biol. Chem., 270, 13834-13841 (1995).

228) Windler EE, Preyer S, Greten H. Influence of lysophosphatidylcholine on the $\mathrm{C}$-apolipoprotein content of rat and human triglyceriderich lipoproteins during triglyceride hydrolysis. J. Clin. Invest., 78, 658-665 (1986).

229) Subbaiah PV, Davidson MH, Ritter MC, Buchanan W, Bagdade JD. Effects of dietary supplementation with marine lipid concentrate on the plasma lipoprotein composition of hypercholesterolemic patients. Atherosclerosis, 79, 157-166 (1989).

230) Memon RA, Holleran WM, Moser AH, Seki T, Uchida Y, Fuller J, Shigenaga JK, Grunfeld C, Feingold KR. Endotoxin and cytokines increase hepatic sphingolipid biosynthesis and produce lipoproteins enriched in ceramides and sphingomyelin. Arterioscler. Thromb. Vasc. Biol., 18, 1257-1265 (1998).

231) Geelen MJ, Tijburg LB, Bouma CJ, Beynen AC. Cholesterol consumption alters hepatic sphingomyelin metabolism in rats. J. Nutr., 125, 2294-2300 (1995).

232) Bladergroen BA, Beynen AC, Geelen MJ. Dietary pectin lowers sphingomyelin concentration in VLDL and raises hepatic sphingomyelinase activity in rats. J. Nutr., 129, 628-633 (1999).

233) Geelen MJ, van Hoorn D, Beynen AC. Consumption of casein instead of soybean protein produces a transient rise in the concentration of sphingomyelin in VLDL in rats. J. Nutr., 129, 2119-2122 (1999).

234) Geelen MJ, Beynen AC. Consumption of olive oil has opposite effects on plasma total cholesterol and sphingomyelin concentrations in rats. Br. J. Nutr., 83, 541-547 (2000).

235) Subbaiah PV, Liu M. Role of sphingomyelin in the regulation of cholesterol esterification in the plasma lipoproteins. Inhibition of lecithin-cholesterol acyltransferase reaction. J. Biol. Chem., 268, 20156-20163 (1993)

236) Laboda HM, Glick JM, Phillips MC. Hydrolysis of lipid monolayers and the substrate specificity of hepatic lipase. Biochim. Biophys. Acta, 876, 233-242 (1986).

237) Myher JJ, Kuksis A, Pind S. Molecular species of glycerophospholipids and sphingomyelins of human plasma: comparison to red blood cells. Lipids, 24, 408-418 (1989).

238) Schissel SL, Jiang X, Tweedie-Hardman J, Jeong T, Camejo EH, Najib J, Rapp JH, Williams KJ, Tabas I. Secretory sphingomyelin- ase, a product of the acid sphingomyelinase gene, can hydrolyze atherogenic lipoproteins at neutral $\mathrm{pH}$. Implications for atherosclerotic lesion development. J. Biol. Chem., 273, 2738-2746 (1998).

239) Jeong T, Schissel SL, Tabas I, Pownall HJ, Tall AR, Jiang X. Increased sphingomyelin content of plasma lipoproteins in apolipoprotein E knockout mice reflects combined production and catabolic defects and enhances reactivity with mammalian sphingomyelinase. J. Clin. Invest., 101, 905-912 (1998).

240) Jiang XC, Paultre F, Pearson TA, Reed RG, Francis CK, Lin M, Berglund L, Tall AR. Plasma sphingomyelin level as a risk factor for coronary artery disease. Arterioscler. Thromb. Vasc. Biol., 20, 2614-2618 (2000).

241) Redgrave TG, Rakic V, Mortimer BC, Mamo JC. Effects of sphingomyelin and phosphatidylcholine acyl chains on the clearance of triacylglycerol-rich lipoproteins from plasma. Studies with lipid emulsions in rats. Biochim. Biophys. Acta, 1126, 65-72 (1992).

242) Takino T, Konishi K, Takakura Y, Hashida M. Long circulating emulsion carrier systems for highly lipophilic drugs. Biol. Pharm. Bull., 17, 121-125 (1994).

243) Arimoto I, Matsumoto C, Tanaka M, Okuhira K, Saito H, Handa T. Surface composition regulates clearance from plasma and triolein lipolysis of lipid emulsions. Lipids, 33, 773-779 (1998).

244) Morita SY, Okuhira K, Tsuchimoto N, Vertut-Doi A, Saito H, Nakano M, Handa T. Effects of sphingomyelin on apolipoprotein E- and lipoprotein lipase-mediated cell uptake of lipid particles. Biochim. Biophys. Acta, 1631, 169-176 (2003).

245) Morita SY, Sakurai A, Nakano M, Kitagawa S, Handa T. Presence of apolipoprotein C-III attenuates apolipoprotein E-mediated cellular uptake of cholesterol-containing lipid particles by HepG2 cells. Lipids, 46, 323-332 (2011).

246) Redgrave TG, Small DM. Quantitation of the transfer of surface phospholipid of chylomicrons to the high density lipoprotein fraction during the catabolism of chylomicrons in the rat. J. Clin. Invest., 64, 162-171 (1979).

247) Ben-Yashar V, Barenholz Y. Characterization of the core and surface of human plasma lipoproteins. A study based on the use of five fluorophores. Chem. Phys. Lipids, 60, 1-14 (1991).

248) Saito H, Minamida T, Arimoto I, Handa T, Miyajima K. Physical states of surface and core lipids in lipid emulsions and apolipoprotein binding to the emulsion surface. J. Biol. Chem., 271, 1551515520 (1996).

249) Sakurai A, Morita SY, Wakita K, Deharu Y, Nakano M, Handa T. Effects of cholesterol in chylomicron remnant models of lipid emulsions on apoE-mediated uptake and cytotoxicity of macrophages. $J$. Lipid Res., 46, 2214-2220 (2005).

250) Maranhao RC, Tercyak AM, Redgrave TG. Effects of cholesterol content on the metabolism of protein-free emulsion models of lipoproteins. Biochim. Biophys. Acta, 875, 247-255 (1986).

251) Wakita K, Morita SY, Okamoto N, Takata E, Handa T, Nakano M. Chylomicron remnant model emulsions induce intracellular cholesterol accumulation and cell death due to lysosomal destabilization. Biochim. Biophys. Acta, 1851, 598-604 (2015).

252) Saito H, Okuhira K, Tsuchimoto N, Vertut-Doi A, Matsumoto C, Tanimoto T, Okada S, Handa T. Modulation of apolipoprotein Emediated plasma clearance and cell uptake of emulsion particles by cholesteryl ester. Lipids, 36, 27-33 (2001).

253) Wang X, Pease R, Bertinato J, Milne RW. Well-defined regions of apolipoprotein B-100 undergo conformational change during its intravascular metabolism. Arterioscler. Thromb. Vasc. Biol., 20, 1301-1308 (2000).

254) Saito H, Dhanasekaran P, Baldwin F, Weisgraber KH, Lund-Katz S, Phillips MC. Lipid binding-induced conformational change in human apolipoprotein E. Evidence for two lipid-bound states on spherical particles. J. Biol. Chem., 276, 40949-40954 (2001).

255) Granot E, Schwiegelshohn B, Tabas I, Gorecki M, Vogel T, Carpentier YA, Deckelbaum RJ. Effects of particle size on cell uptake 
of model triglyceride-rich particles with and without apoprotein E. Biochemistry, 33, 15190-15197 (1994).

256) Breyer ED, Le NA, Li X, Martinson D, Brown WV. Apolipoprotein C-III displacement of apolipoprotein E from VLDL: effect of particle size. J. Lipid Res., 40, 1875-1882 (1999).

257) Rensen PC, Herijgers N, Netscher MH, Meskers SC, van Eck M, van Berkel TJ. Particle size determines the specificity of apolipoprotein E-containing triglyceride-rich emulsions for the LDL receptor versus hepatic remnant receptor in vivo. J. Lipid Res., $\mathbf{3 8}$ 1070-1084 (1997).

258) Weinberg RB, Scanu AM. In vitro reciprocal exchange of apoproteins and nonpolar lipids between human high density lipoproteins and an artificial triglyceride-phospholipid emulsion (Intralipid). Atherosclerosis, 44, 141-152 (1982).

259) MacRaild CA, Hatters DM, Howlett GJ, Gooley PR. NMR structure of human apolipoprotein C-II in the presence of sodium dodecyl sulfate. Biochemistry, 40, 5414-5421 (2001).

260) Nicoll A, Lewis B. Evaluation of the roles of lipoprotein lipase and hepatic lipase in lipoprotein metabolism: in vivo and in vitro studies in man. Eur. J. Clin. Invest., 10, 487-495 (1980).

261) Fisher RM, Coppack SW, Humphreys SM, Gibbons GF, Frayn KN. Human triacylglycerol-rich lipoprotein subfractions as substrates for lipoprotein lipase. Clin. Chim. Acta, 236, 7-17 (1995).

262) Miller KW, Small DM. Triolein-cholesteryl oleate-cholesterol-lecithin emulsions: structural models of triglyceride-rich lipoproteins. Biochemistry, 22, 443-451 (1983).

263) Xiang SQ, Cianflone K, Kalant D, Sniderman AD. Differential binding of triglyceride-rich lipoproteins to lipoprotein lipase. $J$. Lipid Res., 40, 1655-1663 (1999).

264) Yamamoto M, Morita SY, Kumon M, Kawabe M, Nishitsuji K, Saito H, Vertut-Doi A, Nakano M, Handa T. Effects of plasma apolipoproteins on lipoprotein lipase-mediated lipolysis of small and large lipid emulsions. Biochim. Biophys. Acta, 1632, 31-39 (2003).

265) Egashira M, Gorbenko G, Tanaka M, Saito H, Molotkovsky J, Nakano M, Handa T. Cholesterol modulates interaction between an amphipathic class A peptide, Ac-18A-NH2, and phosphatidylcholine bilayers. Biochemistry, 41, 4165-4172 (2002).

266) Masuda D, Sugimoto T, Tsujii K, Inagaki M, Nakatani K, YuasaKawase M, Tsubakio-Yamamoto K, Ohama T, Nishida M, Ishigami M, Kawamoto T, Matsuyama A, Sakai N, Komuro I, Yamashita S. Correlation of fasting serum apolipoprotein B-48 with coronary artery disease prevalence. Eur. J. Clin. Invest., 42, 992-999 (2012).

267) Kawasaki S, Taniguchi T, Fujioka Y, Takahashi A, Takahashi T, Domoto K, Taguchi M, Ishikawa Y, Yokoyama M. Chylomicron remnant induces apoptosis in vascular endothelial cells. Ann. N. Y. Acad. Sci., 902, 336-341 (2000).

268) Fielding CJ. Lipoprotein receptors, plasma-cholesterol metabolism, and the regulation of cellular free-cholesterol concentration. FASEB J., 6, 3162-3168 (1992).

269) Mahley RW, Huang Y. Atherogenic remnant lipoproteins: role for proteoglycans in trapping, transferring, and internalizing. J. Clin. Invest., 117, 94-98 (2007).

270) Krieger M, Herz J. Structures and functions of multiligand lipoprotein receptors: macrophage scavenger receptors and LDL receptorrelated protein (LRP). Annu. Rev. Biochem., 63, 601-637 (1994).

271) Yu KC, Mamo JC. Chylomicron-remnant-induced foam cell formation and cytotoxicity: a possible mechanism of cell death in atherosclerosis. Clin. Sci. (Lond.), 98, 183-192 (2000).

272) Bentley C, Hathaway N, Widdows J, Bejta F, De Pascale C, Avella M, Wheeler-Jones CP, Botham KM, Lawson C. Influence of chylomicron remnants on human monocyte activation in vitro. Nutr. Metab. Cardiovasc. Dis., 21, 871-878 (2011).

273) Graham VS, Di Maggio P, Armengol S, Lawson C, Wheeler-Jones $\mathrm{CP}$, Botham KM. Inhibition of macrophage inflammatory cytokine secretion by chylomicron remnants is dependent on their uptake by the low density lipoprotein receptor. Biochim. Biophys. Acta, 1811,
209-220 (2011).

274) Turk B, Dolenc I, Lenarcic B, Krizaj I, Turk V, Bieth JG, Bjork I. Acidic $\mathrm{pH}$ as a physiological regulator of human cathepsin $\mathrm{L}$ activity. Eur. J. Biochem., 259, 926-932 (1999).

275) Liu J, Sukhova GK, Sun JS, Xu WH, Libby P, Shi GP. Lysosomal cysteine proteases in atherosclerosis. Arterioscler. Thromb. Vasc. Biol., 24, 1359-1366 (2004).

276) Yang AJ, Chandswangbhuvana D, Margol L, Glabe CG. Loss of endosomal/lysosomal membrane impermeability is an early event in amyloid A beta 1-42 pathogenesis. J. Neurosci. Res., 52, 691-698 (1998).

277) Yuan XM, Li W, Brunk UT, Dalen H, Chang YH, Sevanian A. Lysosomal destabilization during macrophage damage induced by cholesterol oxidation products. Free Radic. Biol. Med., 28, 208-218 (2000).

278) Ferri KF, Kroemer G. Organelle-specific initiation of cell death pathways. Nat. Cell Biol., 3, E255-E263 (2001).

279) Guicciardi ME, Deussing J, Miyoshi H, Bronk SF, Svingen PA, Peters C, Kaufmann SH, Gores GJ. Cathepsin B contributes to TNFalpha-mediated hepatocyte apoptosis by promoting mitochondrial release of cytochrome c. J. Clin. Invest., 106, 1127-1137 (2000).

280) Stoka V, Turk B, Schendel SL, Kim TH, Cirman T, Snipas SJ, Ellerby LM, Bredesen D, Freeze H, Abrahamson M, Bromme D, Krajewski S, Reed JC, Yin XM, Turk V, Salvesen GS. Lysosomal protease pathways to apoptosis-Cleavage of Bid, not pro-caspases, is the most likely route. J. Biol. Chem., 276, 3149-3157 (2001).

281) Li W, Kornmark L, Jonasson L, Forssell C, Yuan XM. Cathepsin L is significantly associated with apoptosis and plaque destabilization in human atherosclerosis. Atherosclerosis, 202, 92-102 (2009).

282) Kolesnick RN, Goñi FM, Alonso A. Compartmentalization of ceramide signaling: physical foundations and biological effects. $J$. Cell. Physiol., 184, 285-300 (2000).

283) Marathe S, Schissel SL, Yellin MJ, Beatini N, Mintzer R, Williams KJ, Tabas I. Human vascular endothelial cells are a rich and regulatable source of secretory sphingomyelinase. Implications for early atherogenesis and ceramide-mediated cell signaling. J. Biol. Chem., 273, 4081-4088 (1998).

284) Schissel SL, Tweedie-Hardman J, Rapp JH, Graham G, Williams KJ, Tabas I. Rabbit aorta and human atherosclerotic lesions hydrolyze the sphingomyelin of retained low-density lipoprotein. Proposed role for arterial-wall sphingomyelinase in subendothelial retention and aggregation of atherogenic lipoproteins. J. Clin. Invest., 98, 1455-1464 (1996).

285) Holopainen JM, Medina OP, Metso AJ, Kinnunen PK. Sphingomyelinase activity associated with human plasma low density lipoprotein. J. Biol. Chem., 275, 16484-16489 (2000).

286) Marathe S, Choi Y, Leventhal AR, Tabas I. Sphingomyelinase converts lipoproteins from apolipoprotein $\mathrm{E}$ knockout mice into potent inducers of macrophage foam cell formation. Arterioscler. Thromb. Vasc. Biol., 20, 2607-2613 (2000).

287) Morita SY, Kawabe M, Sakurai A, Okuhira K, Vertut-Doi A, Nakano M, Handa T. Ceramide in lipid particles enhances heparan sulfate proteoglycan and low density lipoprotein receptor-related protein-mediated uptake by macrophages. J. Biol. Chem., 279, 24355-24361 (2004).

288) Morita SY, Nakano M, Sakurai A, Deharu Y, Vertut-Doi A, Handa T. Formation of ceramide-enriched domains in lipid particles enhances the binding of apolipoprotein E. FEBS Lett., 579, 1759-1764 (2005).

289) Korlach J, Schwille P, Webb WW, Feigenson GW. Characterization of lipid bilayer phases by confocal microscopy and fluorescence correlation spectroscopy. Proc. Natl. Acad. Sci. U.S.A., 96, 84618466 (1999).

290) Feigenson GW, Buboltz JT. Ternary phase diagram of dipalmitoylPC/dilauroyl-PC/cholesterol: nanoscopic domain formation driven by cholesterol. Biophys. J., 80, 2775-2788 (2001). 
291) Gousset K, Wolkers WF, Tsvetkova NM, Oliver AE, Field CL, Walker NJ, Crowe JH, Tablin F. Evidence for a physiological role for membrane rafts in human platelets. J. Cell. Physiol., 190, 117128 (2002).

292) Holopainen JM, Subramanian M, Kinnunen PK. Sphingomyelinase induces lipid microdomain formation in a fluid phosphatidylcholine/ sphingomyelin membrane. Biochemistry, 37, 17562-17570 (1998).

293) Gupta AK, Rudney H. Sphingomyelinase treatment of low density lipoprotein and cultured cells results in enhanced processing of LDL which can be modulated by sphingomyelin. J. Lipid Res., 33, 1741-1752 (1992).

294) Tabas I, Li Y, Brocia RW, Xu SW, Swenson TL, Williams KJ. Lipoprotein lipase and sphingomyelinase synergistically enhance the association of atherogenic lipoproteins with smooth muscle cells and extracellular matrix. A possible mechanism for low density lipoprotein and lipoprotein(a) retention and macrophage foam cell formation. J. Biol. Chem., 268, 20419-20432 (1993).

295) Greenberg S. Modular components of phagocytosis. J. Leukoc. Biol., 66, 712-717 (1999).

296) Heuser JE, Anderson RG. Hypertonic media inhibit receptor-mediated endocytosis by blocking clathrin-coated pit formation. J. Cell Biol., 108, 389-400 (1989).

297) Bu G, Maksymovitch EA, Nerbonne JM, Schwartz AL. Expression and function of the low density lipoprotein receptor-related protein (LRP) in mammalian central neurons. J. Biol. Chem., 269, 18521-18528 (1994).

298) Ursini F, Davies KJ, Maiorino M, Parasassi T, Sevanian A. Atherosclerosis: another protein misfolding disease? Trends Mol. Med., 8 , 370-374 (2002).

299) Parasassi T, Bittolo-Bon G, Brunelli R, Cazzolato G, Krasnowska EK, Mei G, Sevanian A, Ursini F. Loss of apoB-100 secondary structure and conformation in hydroperoxide rich, electronegative LDL(-). Free Radic. Biol. Med., 31, 82-89 (2001).
300) Brunelli R, Mei G, Krasnowska EK, Pierucci F, Zichella L, Ursini F, Parasassi T. Estradiol enhances the resistance of LDL to oxidation by stabilizing apoB-100 conformation. Biochemistry, 39, 13897-13903 (2000).

301) Stewart CR, Tseng AA, Mok YF, Staples MK, Schiesser CH, Lawrence LJ, Varghese JN, Moore KJ, Howlett GJ. Oxidation of low-density lipoproteins induces amyloid-like structures that are recognized by macrophages. Biochemistry, 44, 9108-9116 (2005).

302) Asatryan L, Hamilton RT, Isas JM, Hwang J, Kayed R, Sevanian A. LDL phospholipid hydrolysis produces modified electronegative particles with an unfolded apoB-100 protein. J. Lipid Res., 46, 115-122 (2005)

303) Parasassi T, De Spirito M, Mei G, Brunelli R, Greco G, Lenzi L, Maulucci G, Nicolai E, Papi M, Arcovito G, Tosatto SC, Ursini F. Low density lipoprotein misfolding and amyloidogenesis. FASEB J., 22, 2350-2356 (2008).

304) Johs A, Hammel M, Waldner I, May RP, Laggner P, Prassl R. Modular structure of solubilized human apolipoprotein B-100. Low resolution model revealed by small angle neutron scattering. J. Biol. Chem., 281, 19732-19739 (2006).

305) Walsh MT, Atkinson D. Solubilization of low-density lipoprotein with sodium deoxycholate and recombination of apoprotein $\mathrm{B}$ with dimyristoylphosphatidylcholine. Biochemistry, 22, 3170-3178 (1983).

306) Gantz DL, Walsh MT, Small DM. Morphology of sodium deoxycholate-solubilized apolipoprotein B-100 using negative stain and vitreous ice electron microscopy. J. Lipid Res., 41, 1464-1472 (2000).

307) Morita SY, Deharu Y, Takata E, Nakano M, Handa T. Cytotoxicity of lipid-free apolipoprotein B. Biochim. Biophys. Acta, 1778, 2594-2603 (2008).

308) Jayaraman S, Gantz DL, Gursky O. Effects of oxidation on the structure and stability of human low-density lipoprotein. Biochemistry, 46, 5790-5797 (2007). 